\title{
Article \\ Chrysosplenol D Triggers Apoptosis through Heme Oxygenase-1 and Mitogen-Activated Protein Kinase Signaling in Oral Squamous Cell Carcinoma
}

\author{
Ming-Ju Hsieh 1,2,3,4 (D), Chia-Chieh Lin ${ }^{1}$, Yu-Sheng Lo ${ }^{1}$, Yi-Ching Chuang ${ }^{1}$, Hsin-Yu Ho ${ }^{1, *(D)}$ \\ and Mu-Kuan Chen ${ }^{5, *}$ \\ 1 Oral Cancer Research Center, Changhua Christian Hospital, Changhua 500, Taiwan; \\ 170780@cch.org.tw (M.-J.H.); 181327@cch.org.tw (C.-C.L.); 165304@cch.org.tw (Y.-S.L.); \\ 177267@cch.org.tw (Y.-C.C.) \\ 2 College of Medicine, National Chung Hsing University, Taichung 402, Taiwan \\ 3 Institute of Medicine, Chung Shan Medical University, Taichung 402, Taiwan \\ 4 Graduate Institute of Biomedical Sciences, China Medical University, Taichung 404, Taiwan \\ 5 Department of Otorhinolaryngology, Head and Neck Surgery, Changhua Christian Hospital, \\ Changhua 500, Taiwan \\ * Correspondence: 183581@cch.org.tw (H.-Y.H.); 53780@cch.org.tw (M.-K.C.); \\ Tel.: +886-4-7238595 (H.-Y.H. \& M.-K.C.); Fax: +886-4-7232942 (H.-Y.H. \& M.-K.C.)
}

\section{check for}

updates

Citation: Hsieh, M.-J.; Lin, C.-C.; Lo, Y.-S.; Chuang, Y.-C.; Ho, H.-Y.; Chen, M.-K. Chrysosplenol D Triggers Apoptosis through Heme

Oxygenase-1 and Mitogen-Activated Protein Kinase Signaling in Oral Squamous Cell Carcinoma. Cancers 2021, 13, 4327. https://doi.org/ 10.3390/cancers13174327

Academic Editors: Andrea Santarelli and Mary Frances McMullin

Received: 27 July 2021

Accepted: 25 August 2021

Published: 27 August 2021

Publisher's Note: MDPI stays neutral with regard to jurisdictional claims in published maps and institutional affiliations.

Copyright: (c) 2021 by the authors. Licensee MDPI, Basel, Switzerland. This article is an open access article distributed under the terms and conditions of the Creative Commons Attribution (CC BY) license (https:// creativecommons.org/licenses/by/ $4.0 /)$.
Simple Summary: Oral squamous cell carcinoma (OSCC) accounts for the most malignancies. A GLO-BOCAN 2020 report estimated 377,713 new cases of oral cancer and 177,757 deaths due to oral cancer in 2020. Chrysosplenol D, a flavonol isolated from Artemisia annua L., can exert an-ticancer effects. This study investigated the anticancer property of chrysosplenol D and its un-derlying mechanism in oral squamous cell carcinoma. We observed that chrysosplenol D reduced cell viability, cell cycle arrest, apoptosis and autophagy in OSCC. Moreover, the upregulation of heme oxygenase-1 (HO-1) was found to be critical for chrysosplenol D-induced apoptotic cell death that patients with head and neck cancer had lower HO-1 expression. The findings of the present study indicated that chrysosplenol D exerts anticancer effects on OSCC by suppressing the MAPK pathway and activating HO-1 expression. Suggest that chrysosplenol D might be a potential anticancer agent for treating OSCC.

Abstract: Chrysosplenol D, a flavonol isolated from Artemisia annua L., can exert anticancer effects. This study investigated the anticancer property of chrysosplenol D and its underlying mechanism in oral squamous cell carcinoma (OSCC). We observed that chrysosplenol D reduced cell viability and caused cell cycle arrest in the $\mathrm{G}_{2} / \mathrm{M}$ phase. The findings of annexin $\mathrm{V} /$ propidium iodide staining, chromatin condensation, and apoptotic-related protein expression revealed that chrysosplenol D regulated apoptosis in OSCC. Furthermore, chrysosplenol D altered the expression of the autophagy marker LC3 and other autophagy-related proteins. Phosphatidylinositol 3-kinase/protein kinase B, extracellular signal-regulated kinase, c-Jun N-terminal kinase, and p38 mitogen-activated protein kinase (MAPK) were downregulated by chrysosplenol D, and the inhibition of these pathways significantly enhanced chrysosplenol D-induced cleaved poly (ADP-ribose) polymerase activation. Moreover, the upregulation of heme oxygenase-1 (HO-1) was found to be critical for chrysosplenol D-induced apoptotic cell death. The analysis of clinical data from The Cancer Genome Atlas and Gene Expression Omnibus datasets revealed that patients with head and neck cancer had lower HO-1 expression than did those with no head and neck cancer. The findings of the present study indicated that chrysosplenol D exerts anticancer effects on OSCC by suppressing the MAPK pathway and activating HO-1 expression.

Keywords: chrysosplenol D; apoptosis; autophagy; heme oxygenase-1; oral squamous cell carcinoma 


\section{Introduction}

Among head and neck cancers, oral cancer results in higher morbidity than other head and neck cancers [1]. Oral cancer may originate in any part of the oral tissue and has different histological types. Oral squamous cell carcinoma (OSCC) accounts for the most malignancies. A GLOBOCAN 2020 report estimated 377,713 new cases of oral cancer and 177,757 deaths due to oral cancer in 2020 [2]. The incidence of oral cancer is high in Melanesia and South-Central Asia owing to the habit of betel nut chewing in these areas [3]. Furthermore, the incidence of oral cancer increased with age and was higher in men than in women in most regions [4]. Surgery remains the mainstay treatment for OSCC, and adjuvant therapies, such as chemoradiotherapy, epidermal growth factor receptor and cyclooxygenase-2 inhibitors, and photodynamic therapy, are used for patients with advanced disease $[5,6]$. Although the survival rate of patients with OSCC has been improving year by year, their prognosis is relatively poor with a high recurrence rate [7]. With the increasing incidence rates of all cancers, 28.4 million new cancer cases are predicted to occur in 2040, indicating a $47 \%$ increase in the number of cancer cases from 19.3 million new cancer cases reported in 2020 [2]. Therefore, new anticancer agents should be urgently developed.

Autophagy and apoptosis are distinct self-destructive processes that determine the turnover of cytoplasmic organelles and proteins. Autophagy involves the fusion of doublemembrane vesicles, such as autophagosomes, with lysosomes to form autolysosomes, and the degradation of autophagic cargo occurs in autolysosomes [8]. Autophagy is a cellular process that protects cells against low-nutrient conditions through the participation of autophagy-related proteins [9]. Apoptosis is a type of programmed cell death and involves a series of morphological changes such as chromatin condensation, fragmentation, and apoptotic body formation [10,11]. In addition, apoptosis is characterized by biochemical changes, including apoptosis-related protein regulation (e.g., Bcl-2 family proteins), mitochondrial outer membrane permeabilization, and cysteine-aspartic protease (caspase) activation $[12,13]$. These two catabolic pathways are essential for organismal homeostasis and thus protect organisms against cancer $[14,15]$. The autophagic process mainly removes damaged organelles and proteins from cells. Tumor cells have autophagic defects that might inhibit autophagic cell death [16-18]. However, starvation-mediated autophagy might promote tumor survival by degrading cellular building blocks to provide nutrients for tumor cells under hypoxic and nutrient-limiting conditions $[19,20]$. Hence, autophagy appears to be a double-edged sword in cancer. Apoptosis is considered a tumor suppressor pathway. The disruption of both extrinsic and intrinsic pathways has been observed in several cancers. For instance, in the extrinsic pathway, the disruption often occurs due to changes in the localization of death receptors and the downregulation of the surface expression of death receptors [21,22]. In the intrinsic pathway, the disruption often occurs due to the overexpression of antiapoptotic proteins and the inactivation of proapoptotic proteins [21].

The heme oxygenase-1 (HMOX-1) gene encodes an essential enzyme HO- 1 that is involved in heme catabolism and cleaves heme to form biliverdin, carbon monoxide, and ferrous iron. HO-1 is expressed in various types of cancers and is positively correlated with poor prognosis in patients with cancers [23]. HO-1 overexpression in cancer cells promotes proliferation, invasion, and survival [24-26]. However, recent studies have indicated the antitumor effects of HO-1. Gandini et al. found that HO-1 activation induced apoptosis and inhibited migration and invasion by modulating epithelial-mesenchymal transition (EMT) in breast cancer cells [27]. In addition, Yanagawa et al. reported that low HO-1 expression is correlated with an increased risk of lymph node metastasis in OSCC [28]. These findings indicate the dual role of HO-1 in cancer progression. However, the role of HO-1 in OSCC still needs further investigation.

Artemisia annua $\mathrm{L}$. is a Chinese traditional medicine that is widely used to treat fever. Artemisinin, a sesquiterpene lactone isolated from $A$. annua L., exerts antiparasitic and anticancer effects $[29,30]$. In addition, $A$. annua $\mathrm{L}$. contains various phenolic compounds 
including phenolic acids, flavonols, and flavones [31]. Few studies have reported the anticancer and anti-inflammatory properties of chrysosplenol $\mathrm{D}$, a flavonol isolated from A. annua L. [32,33]. Moreover, flavonols such as casticin, quercetin, and kaempferol have been reported to promote cancer cell apoptosis [34-36]. On the basis of these findings, we hypothesized that chrysosplenol D would inhibit cancer cell proliferation in OSCC. Thus, in this study, we investigated the effects of chrysosplenol D on OSCC and elucidated its mechanism underlying cell apoptosis. In addition, we evaluated the effect of HO-1 on chrysosplenol D-treated OSCC.

\section{Materials and Methods}

\subsection{Chemicals and Reagents}

Chrysosplenol D (purity $\geq 98 \%$ ) was purchased from ChemFaces (Wuhan Chem Faces Biochemical Co., Ltd., Wuhan, China) and dissolved in dimethyl sulfoxide (DMSO) to obtain a solution of $100 \mathrm{mM}$. Furthermore, 3-(4, 5-imethylthiazol-2-yl)-2, 5-diphenyltetrazolium bromide (MTT), 4,6-diamidino-2-phenylindole (DAPI), protease inhibitor cocktail, and phosphatase inhibitor cocktail were purchased from Sigma Aldrich (St Louis, MO, USA). Primary antibodies were purchased from Cell Signaling Technology (Danvers, MA, USA). Secondary antibodies were purchased from Jackson ImmunoResearch (West Grove, PA, USA). The final concentration of DMSO used in all treatments was $<0.1 \%$.

\subsection{Cell Lines and Cell Culture}

Human OSCC cell lines, namely SCC-9 and HSC-3, were purchased from the American Type Culture Collection (Manassas, VA, USA). The OECM-1 cell line was purchased from Bioresource Collection and Research Center (Hsinchu, Taiwan). The HSC-3-M3 cell line, which has a high metastatic potential for lymph nodes in human OSCC, is derived from the HSC-3 cell line. The HSC-3-M3 cell line was purchased from the Japanese Collection of Research Bioresources Cell Bank (Japan). For culturing, SCC-9 cells were grown in Dulbecco's modified Eagle's medium (DMEM): nutrient mixture F12 medium (Gibco BRL, Grand Island, NY, USA) supplemented with 10\% fetal bovine serum (FBS), $1 \mathrm{mM}$ L-glutamine, $1 \%$ penicillin/streptomycin, $1.5 \mathrm{~g} / \mathrm{L}$ sodium bicarbonate, and $1 \mathrm{mM}$ sodium pyruvate (Sigma Aldrich). HSC-3 cells were grown in DMEM medium (Gibco BRL) supplemented with $10 \%$ FBS, $1 \mathrm{mM}$ glutamine, $1 \%$ penicillin/streptomycin, and $1.5 \mathrm{~g} / \mathrm{L}$ sodium bicarbonate. OECM-1 cells were grown in RPMI 1640 medium (Gibco BRL) supplemented with $10 \%$ FBS, $1 \%$ penicillin/streptomycin, $2.5 \mathrm{mM}$ HEPES, and $1.5 \mathrm{~g} / \mathrm{L}$ sodium bicarbonate. HSC-3-M3 cells were grown in minimal essential medium (Gibco BRL) supplemented with 10\% FBS, $1 \mathrm{mM} \mathrm{L-glutamine,} 1 \%$ penicillin/streptomycin, and $1.5 \mathrm{~g} / \mathrm{L}$ of sodium bicarbonate. All cell lines were maintained at $37{ }^{\circ} \mathrm{C}$ in a humidified atmosphere of $5 \% \mathrm{CO}_{2}$.

\subsection{Cell Viability Assay}

Cells seeded in a 96-well plate were treated with the indicated doses of chrysosplenol $\mathrm{D}(0,25,50$, and $100 \mu \mathrm{M})$ for 24,48 , and $72 \mathrm{~h}$, respectively. After treatment, $5 \mathrm{mg} / \mathrm{mL}$ of MTT was added to the plate with conditioned medium for $3 \mathrm{~h}$. Subsequently, formazan accumulated in cells was dissolved in DMSO, and absorbance was measured at a wavelength of $595 \mathrm{~nm}$ by using a microplate reader (BioTek, Winooski, VT, USA).

\subsection{Clonogenic Assay}

The clonogenic assay is a cell survival assay based on the growth of a single cell into a colony [37]. Briefly, SCC-9, HSC-3, OECM-1, and HSC-3-M3 cells were counted and seeded in 6-well plates, respectively. After cell adhesion, the indicated doses of chrysosplenol D $(0$, 25,50 , and $100 \mu \mathrm{M}$ ) were added to the wells. To maintain adequate nutrition, the culture medium was replaced every 3 days. After 2 weeks, colonies formed were fixed with $4 \%$ paraformaldehyde for $10 \mathrm{~min}$, stained with $0.5 \%$ crystal violet for $10 \mathrm{~min}$, and counted under a stereomicroscope. 


\subsection{Cell Cycle Analysis}

Cells treated with the indicated doses of chrysosplenol $\mathrm{D}(0,25,50$, and $100 \mu \mathrm{M})$ were collected and fixed with $70 \%$ ethanol for $24 \mathrm{~h}$ at $-20{ }^{\circ} \mathrm{C}$. After discarding ethanol, we incubated cells with the Muse cell cycle reagent (Merck Millipore, Burlington, MA, USA) for $30 \mathrm{~min}$ in the dark. Subsequently, cell cycle distribution was measured using a Muse cell analyzer flow cytometer (Merck Millipore), and data were analyzed using Muse Cell Soft V1.4.0.0 Analyzer Assays (Merck Millipore).

\subsection{Western Blot Analysis}

Western blotting is a technique used to measure the protein of interest through separation based on molecular weights [38]. Briefly, cells treated with the indicated doses of chrysosplenol $\mathrm{D}(0,25,50$, and $100 \mu \mathrm{M})$ were collected and lysed using radioimmunoprecipitation assay buffer (protease and phosphatase inhibitor cocktails were added to prevent protein degradation). Appropriate amounts of proteins were separated through sodium dodecyl sulfate-polyacrylamide gel electrophoresis and then transferred onto $0.22-\mu \mathrm{m}$ polyvinylidene fluoride membranes. Subsequently, the membranes were blocked with $5 \%$ skimmed milk in tris-buffered saline/Tween-20 buffer and incubated with primary antibodies against cyclin A; cyclin B; cyclin D3; cyclin E2; cyclin-dependent kinase (CDK)2; CDK4; CDK6; p21; p27; tumor necrosis factor receptor type 1-associated death domain (TRADD); decoy receptor 2 (DcR2); death receptor 5 (DR5); Bax; Bak; Bcl-xL; Bcl-2; cleaved poly (ADP-ribose) polymerase (PARP); cleaved caspase-3, -8, and -9; long chain 3 (LC3)-I/II; p62/SQSTM1; Beclin-1; autophagy-related gene (Atg)5-Atg12 complex; phospoprotein kinase B (AKT); total-AKT; phospo-extracellular signal-regulated kinase (ERK)1/2; total-ERK1/2; phospo-p38 mitogen-activated protein kinase (MAPK); p38 MAPK; phospoc-Jun N-terminal kinase (JNK)1/2; JNK1/2; and $\beta$-actin (dilution ratio: 1:1000) overnight at $4^{\circ} \mathrm{C}$, respectively. After discarding primary antibodies, we incubated the membranes with horseradish peroxidase-conjugated secondary antibodies. Subsequently, bound antibodies on the membranes were visualized using an enhanced chemiluminescent detection kit (Merck Millipore). The results were quantitated using ImageQuant LAS 4000 Mini (GE Healthcare Life Sciences, Boston, MA, USA).

\subsection{Chromatin Condensation Assay}

The protocol for the chromatin condensation assay has been described previously [39]. Briefly, cells treated with the indicated doses of chrysosplenol D $(0,25,50$, and $100 \mu \mathrm{M})$ were seeded in an 8-well glass chamber slide for $24 \mathrm{~h}$. Subsequently, cells were fixed with $4 \%$ paraformaldehyde and stained with DAPI $(50 \mathrm{mg} / \mathrm{mL})$. Images were observed using the Olympus FluoView FV1200 confocal microscope (Olympus Corporation, Shinjuku, Tokyo, Japan).

\subsection{Annexin V/Propidium Iodide Double Staining}

Cells treated with the indicated doses of chrysosplenol $\mathrm{D}(0,25,50$, and $100 \mu \mathrm{M})$ were collected and resuspended in phosphate-buffered saline (PBS) with $2 \%$ bovine serum albumin (BSA). Subsequently, cells were incubated with annexin V-fluorescein isothiocyanate solution and propidium iodide (PI) solution (BD Biosciences, San Jose, CA, USA) in the dark. The percentage of apoptotic cells was measured using a BD Accuri C6 Plus flow cytometer (BD Biosciences), and data were analyzed using BD CSampler Plus software (BD Biosciences).

\subsection{Mitochondrial Membrane Potential Analysis}

The detailed procedure for mitochondrial membrane potential analysis has been described previously [40]. Briefly, cells treated with chrysosplenol D $(0$ and $100 \mu \mathrm{M})$ were collected and stained with Muse MitoPotential dye. Subsequently, 7-aminoactinomycin $\mathrm{D}$ was added to cells for $5 \mathrm{~min}$ to detect cell viability. Cell signals were measured using a 
Muse cell analyzer flow cytometer, and data were analyzed using Muse Cell Soft V1.4.0.0 Analyzer Assays.

\subsection{In Situ Immunofluorescence Assay}

Cells at density of $4 \times 10^{5} /$ well were seeded in a 6-well plate. After chrysosplenol $\mathrm{D}$ treatment for $24 \mathrm{~h}$, cells were fixed with $4 \%$ paraformaldehyde for $20 \mathrm{~min}$ and then incubated with $0.5 \%$ Triton X-100 for $10 \mathrm{~min}$. After washing cells with PBS and drying the residual solvent, cells were fixed with $4 \%$ paraformaldehyde and then incubated with 5\% BSA at room temperature for the blocking step. Cells were incubated with the LC3-I/II primary antibody overnight at $4{ }^{\circ} \mathrm{C}$. The next day, cells were washed and incubated with the Alexa Fluor 488-conjugated Affinipure goat anti-rabbit immunoglobulinG secondary antibody (Jackson Immuno Research, West Grove, PA, USA) for $1 \mathrm{~h}$. At the end of incubation, cells were observed under a fluorescence microscope equipped with filters for UV and blue light at $488 \mathrm{~nm}$.

\subsection{Autophagosome Detection Assay}

The detailed procedure for the detection of autophagic cells has been described previously [41,42]. Cells were seeded in an 8-well glass chamber slide, followed by treatment with chrysosplenol D $(0,25,50$, and $100 \mu \mathrm{M})$ for $24 \mathrm{~h}$. Cells were stained using a cell meter autophagy assay kit (green fluorescence; AAT Bioquest, Sunnyvale, CA, USA). Autophagosomes were observed under an Olympus FluoView FV1200 confocal microscope (Olympus Corporation).

\subsection{Specific Inhibitor Treatments}

All specific inhibitors were purchased from ChemFaces. LY294002, a phosphatidylinositol 3-kinase (PI3K) / AKT inhibitor, and MAPK inhibitors, namely SP600125 (JNK inhibitor), U0126 (ERK inhibitor), and SB203580 (p38 inhibitor), were dissolved in DMSO as stocks, respectively. Cells were treated with either chrysosplenol D, specific inhibitors (PI3K/AKT, JNK, ERK, or p38 inhibitor), or both. For the co-treatment group, cells were treated with each inhibitor for $1 \mathrm{~h}$. Subsequently, chrysosplenol D $(100 \mu \mathrm{M})$ was added, and cells were incubated for $24 \mathrm{~h}$. The final concentration of DMSO for all treatments was $<0.1 \%$.

\subsection{RNA Interference Experiments}

Human small-interfering ribonucleic acids (siRNAs) for HO-1 and scrambled siRNA were purchased from Cohesion Biosciences (London, UK). Cells were transfected with each siRNA by using the Turbofect reagent (Thermo Fisher Scientific; Waltham, MA, USA) according to the manufacturer's instructions.

\subsection{The Cancer Genome Atlas Database Analysis}

By using head and neck squamous cell carcinoma (HNSCC) tissues, we analyzed the mRNA expression level of HMOX1 between tumor $(n=520)$ and normal $(n=44)$ groups. Data regarding 43 paired tumor samples and normal adjacent tissue samples were obtained from The Cancer Genome Atlas (TCGA) database.

\subsection{Gene Expression Omnibus Dataset Analysis}

Expression data were extracted from the Gene Expression Omnibus (GEO) dataset (GSE3524) and analyzed using GraphPad Prism, V6.0 (GraphPad Software, Inc., CA, USA). The mRNA expression level of HMOX1 was compared between normal and OSCC tissues.

\subsection{Statistical Analysis}

All statistical analyses were performed using GraphPad Prism, V6.0 (GraphPad Software, Inc., CA, USA). All values calculated using Student's $t$ test are presented as the mean \pm standard deviation (SD) from three independent experiments. Differences were considered significant at a $p$ value of $<0.05$. 


\section{Results}

3.1. Chrysosplenol D Exhibits Antiproliferative Activity and Causes Cell Cycle Arrest in the $G_{2} / M$ Phase in Oral Squamous Cell Carcinoma (OSCC) Cell Lines

To investigate the anticancer activity of chrysosplenol D, we first analyzed the viability of OSCC cell lines treated with chrysosplenol D by using the MTT and colony formation assays. SCC-9, OECM-1, HSC-3, and HSC-3-M3 cells were treated with different doses of chrysosplenol D $(0,25,50$, and $100 \mu \mathrm{M})$ for 24,48 , and $72 \mathrm{~h}$, respectively (Figure $1 \mathrm{~A})$. We observed that the viability of these four cell lines significantly decreased in dose- and timedependent manners. Furthermore, the findings of the colony formation assay revealed the anti-proliferative effect of chrysosplenol D on OSCC cell lines (Figure 1B,C). We observed that the HSC-3-M3 cell line, a highly metastatic cell line derived from the HSC-3 cell line, exhibited similar sensitivity to chrysosplenol D-induced cell toxicity as did the HSC-3 cell line. Thus, we selected SCC-9, OECM-1, and HSC-3 cell lines for subsequent experiments.
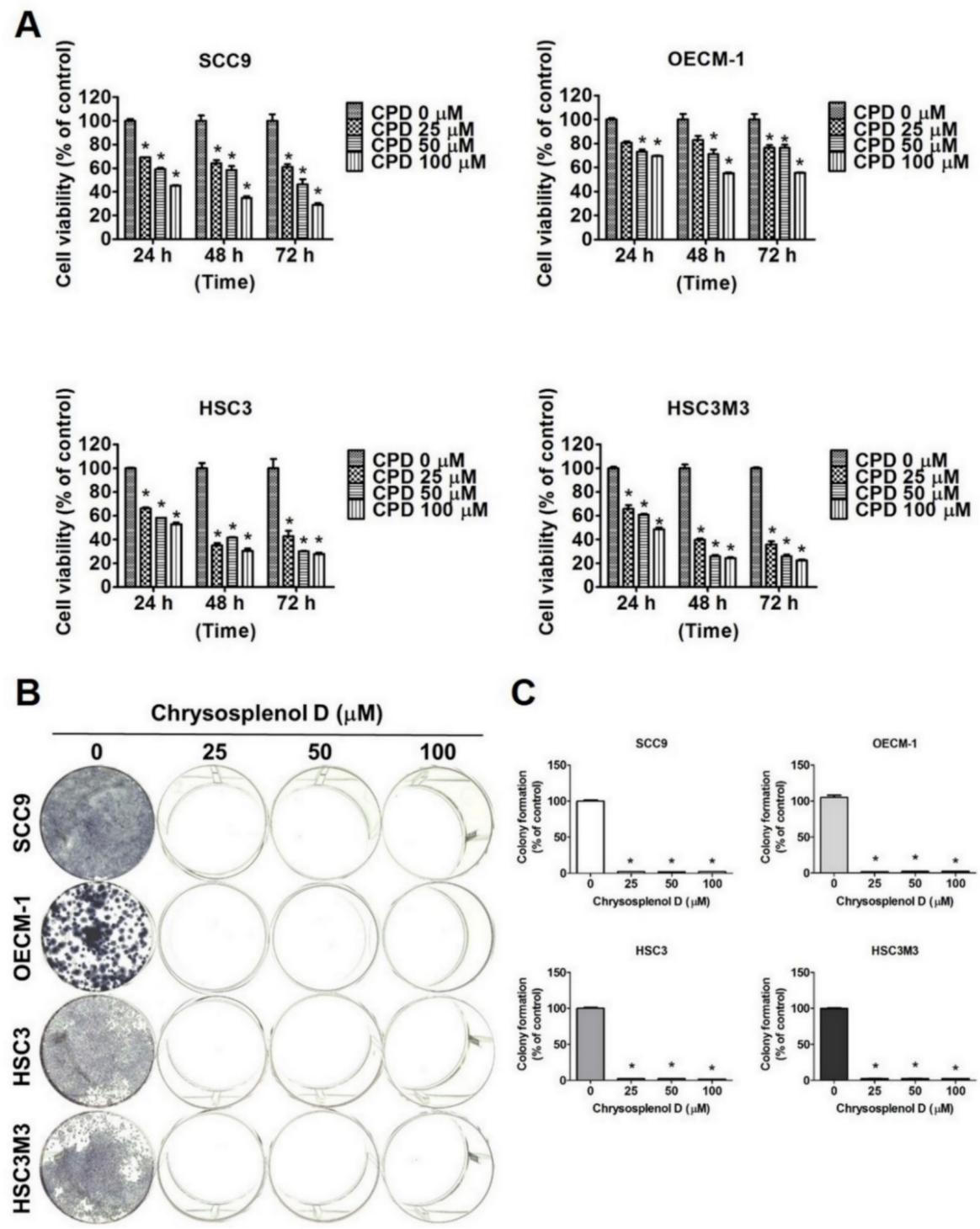

C
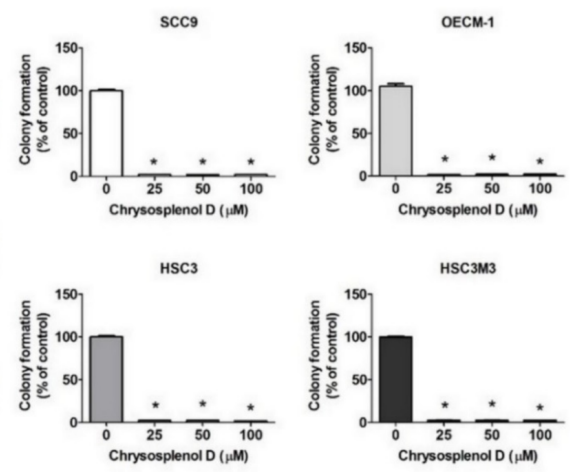

Figure 1. Chrysosplenol D inhibited the proliferation of oral cancer cell lines. (A) Human oral cancer cell lines (SCC-9, OECM-1, HSC-3, and HSC-3-M3) were treated with the indicated doses of chrysosplenol D (0, 25, 50, and $100 \mu \mathrm{M})$ for 24,48 , and $72 \mathrm{~h}$, respectively. Cell viability was measured using the MTT assay (B,C) Cell lines were incubated with the indicated doses of chrysosplenol D $(0,25,50$, and $100 \mu \mathrm{M})$ for 14 days, and the culture medium was replaced every 3 days. Graphs show the findings of statistical analysis. Data are presented as the mean \pm SD from three independent experiments * $p<0.05$ compared with the vehicle treatment group. 
Next, to elucidate mechanisms underlying chrysosplenol D-induced cell growth inhibition, we performed cell cycle analysis through flow cytometry. As shown in Figure 2A,B, in the chrysosplenol D-treated groups, cell cycle distribution was significantly increased in the $\mathrm{G}_{2} / \mathrm{M}$ phase but attenuated in the $\mathrm{G}_{0} / \mathrm{G}_{1}$ phase. In addition, cell cycle distribution in the $S$ phase increased in a dose-dependent manner in SCC-9 cells after treatment with different doses of chrysosplenol D. The cell cycle is controlled through cyclins, a group of family proteins, by activating CDKs. We observed that the protein expressions of cyclin A, cyclin B, cyclin D3, cyclin E2, CDK2, CDK4, and CDK6 were significantly attenuated after chrysosplenol D treatment (Figure 2C,D). However, we noted an increased expression of CDK inhibitors, namely p21 and p27, in SCC-9, OECM-1, and HSC-3 cells. These results indicate that cell cycle arrest in OSCC may contribute to the anti-proliferative effect of chrysosplenol D.

\subsection{Apoptotic Effect of Chrysosplenol D on OSCC Cell Lines}

We examined the morphological and biochemical hallmarks of apoptosis to investigate the apoptotic effect of chrysosplenol D on OSCC cell lines [43]. Cells treated with different doses of chrysosplenol D were stained with DAPI and observed under a fluorescence microscope. Chromatin condensation, the morphological hallmark of apoptosis marked by increased bright blue fluorescence, was observed in chrysosplenol D-treated SCC-9, OECM-1, and HSC-3 cells (Figure 3A,B). Furthermore, the percentage of apoptotic cells was measured through annexin V and PI staining and flow cytometry. As shown in Figure 3C,D, total apoptotic OSCC cells, including early and late apoptotic cells, were increased to 3-4-fold after treatment with chrysosplenol D. Mitochondrial dysfunction is involved in the induction of apoptosis, thus increasing the depolarization of the transmembrane potential [44]. As shown in Figure 4A,B, the percentage of depolarized cells increased after treatment with a high dose of chrysosplenol D $(100 \mu \mathrm{M})$.

To examine whether chrysosplenol D exerts the apoptotic effect through intrinsic and extrinsic pathways (the two main pathways of apoptosis), we evaluated cell lysis in the chrysosplenol D- and vehicle-treated groups by performing Western blot analysis. The expression of extrinsic pathway (death receptor pathway)-related proteins, namely TRADD, DcR2, and DR5, was significantly increased in OSCC cell lines (Figure 4C,D). Furthermore, the expression of proapoptotic (Bax and Bak) and antiapoptotic (Bcl-xL and Bcl-2) proteins involved in regulating apoptosis was increased and decreased, respectively, after chrysosplenol D treatment (Figure 5A,B). In addition, the expression of cleaved caspase-3, -8 , and -9 and cleaved PARP that participate in the intrinsic pathway was increased after chrysosplenol D treatment (Figure 5C,D). These results demonstrate that chrysosplenol D might activate apoptosis through both intrinsic and extrinsic pathways. 


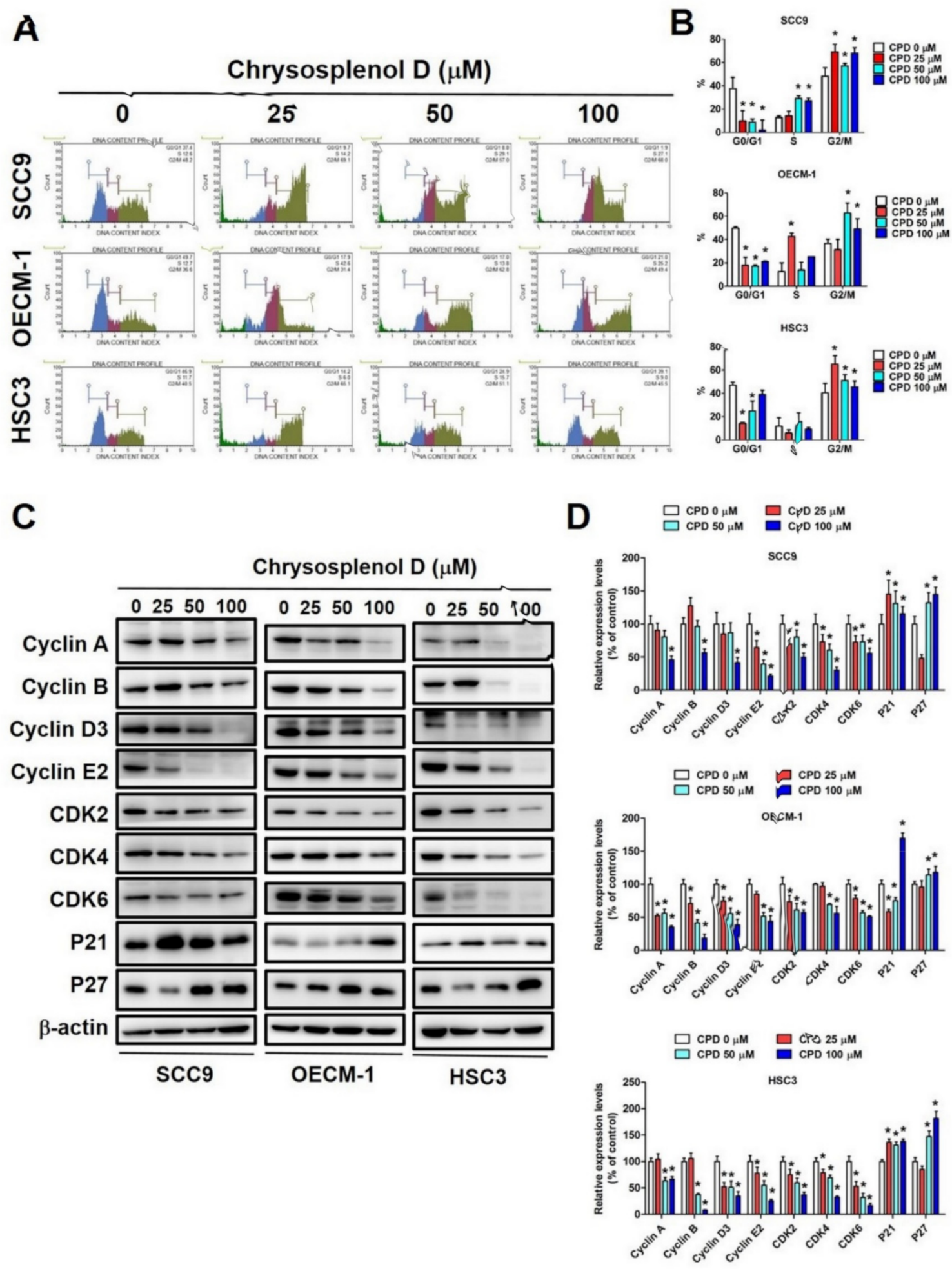

Figure 2. Chrysosplenol $D$ induced cell cycle arrest in the $\mathrm{G}_{2} / \mathrm{M}$ phase in oral squamous cell carcinoma (OSCC) cell lines. (A,B) After the treatment of SCC-9, OECM-1, and HSC-3 cells with chrysosplenol (0, 25, 50, and $100 \mu \mathrm{M})$ for $24 \mathrm{~h}$, cell cycle phase distribution was analyzed through flow cytometry after propidium iodide (PI) staining. Graphs show the findings of statistical analysis. (C,D) The expression levels of cell cycle-regulating proteins, namely cyclin A, cyclin B, cyclin D3, cyclin E2, CDK2, CDK4, CDK6, p21 and p27, were detected through Western blot analysis after chrysosplenol D treatment for $24 \mathrm{~h}$. The $\beta$-actin protein level was used to adjust quantitative results. Graphs show the findings of the statistical analysis of cell cycle-regulating proteins. Data are presented as the mean \pm SD from three independent experiments * $p<0.05$ compared with the vehicle treatment group. 
A

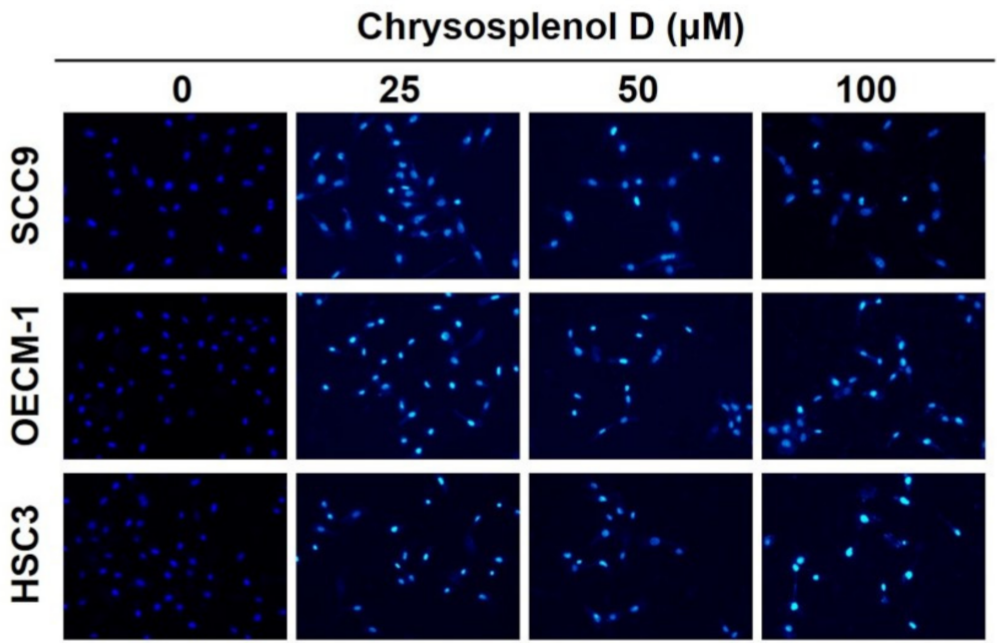

C

\section{Chrysosplenol D $(\mu \mathrm{M})$}
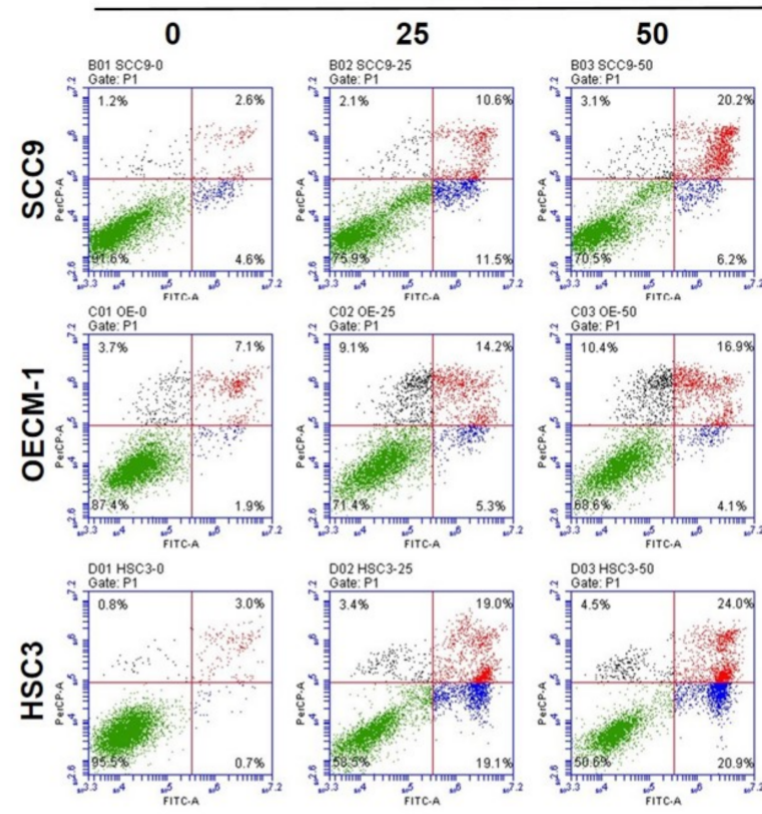
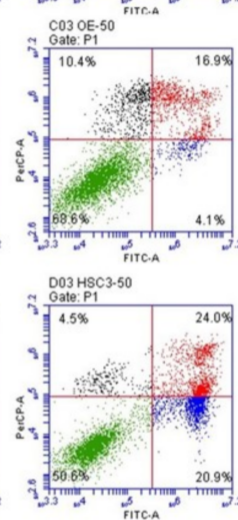

B
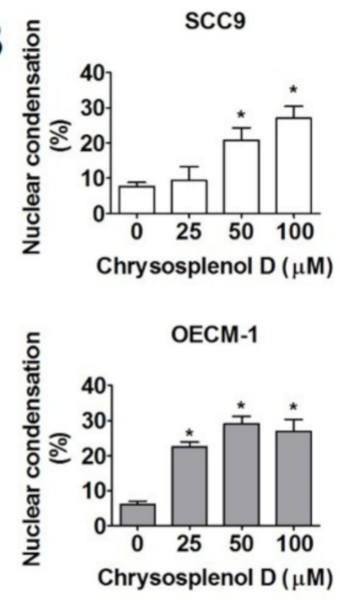

HSC-3

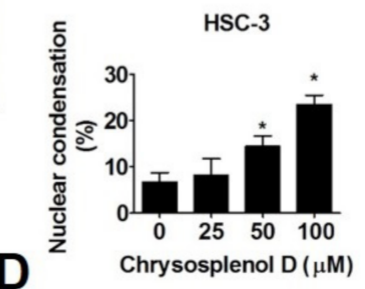

scc9

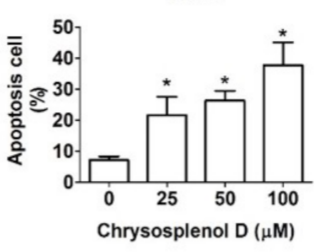

OECM-1

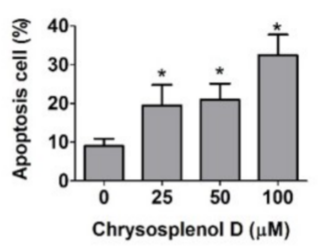

HSC3

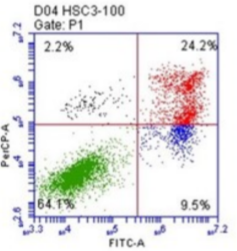

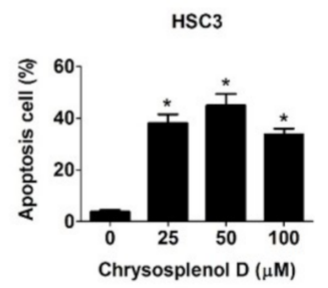

Figure 3. Chrysosplenol D induced apoptotic cell death in OSCC cell lines. (A,B) The morphological characteristics of apoptosis were analyzed through fluorescence microscopy after 4,6-diamidino-2-phenylindole (DAPI) staining in chrysosplenol D-treated OSCC cell lines. The bright-blue spots indicated chromatin condensation, which served as an apoptotic indicator. Graphs show the findings of the statistical analysis of chromatin condensation. (C,D) After the treatment of SCC-9, OECM-1, and HSC-3 cells with chrysosplenol D for $24 \mathrm{~h}$, cell apoptosis was detected through annexin V and PI double staining and flow cytometry. Graphs show the findings of the statistical analysis of annexin V/PI staining and flow cytometry. Data are presented as the mean \pm SD from three independent experiments ${ }^{*} p<0.05$ compared with the vehicle treatment group. 
A
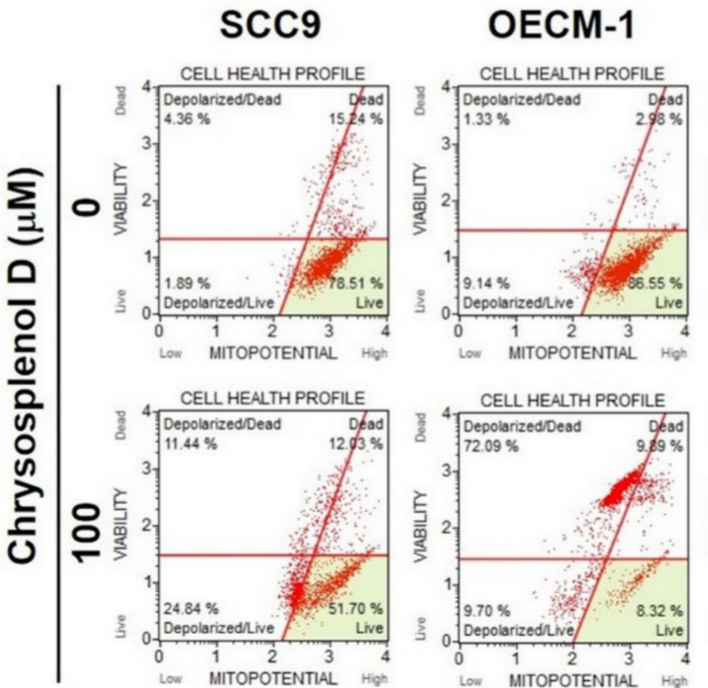

HSC3

B
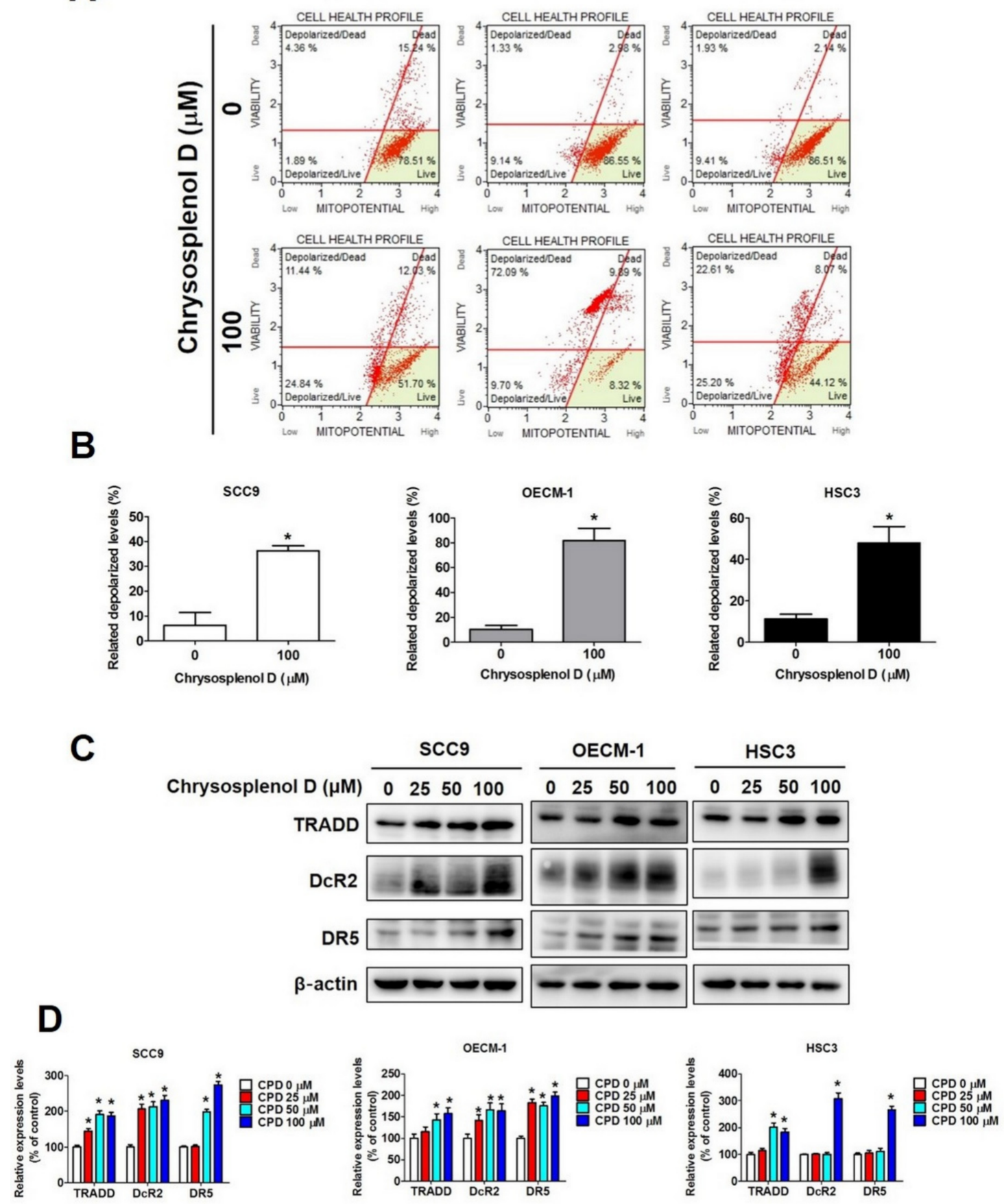

D

Figure 4. Chrysosplenol D regulated the mitochondrial membrane potential and death pathway in OSCC cell lines. $(\mathbf{A}, \mathbf{B})$ After chrysosplenol D $(100 \mu \mathrm{M})$ treatment for $24 \mathrm{~h}$, OSCC cells were collected and measured using a Muse cell analyzer. Quantitative data were analyzed using Muse cell software V1.4.0.0. (C,D) The expression level of death receptor proteins, namely TRADD, DcR2, and DR5, was measured through Western blot analysis. The $\beta$-actin protein level was used to adjust quantitative results. Data are presented as the mean $\pm \mathrm{SD}$ from three independent experiments * $p<0.05$ compared with the vehicle treatment group. 


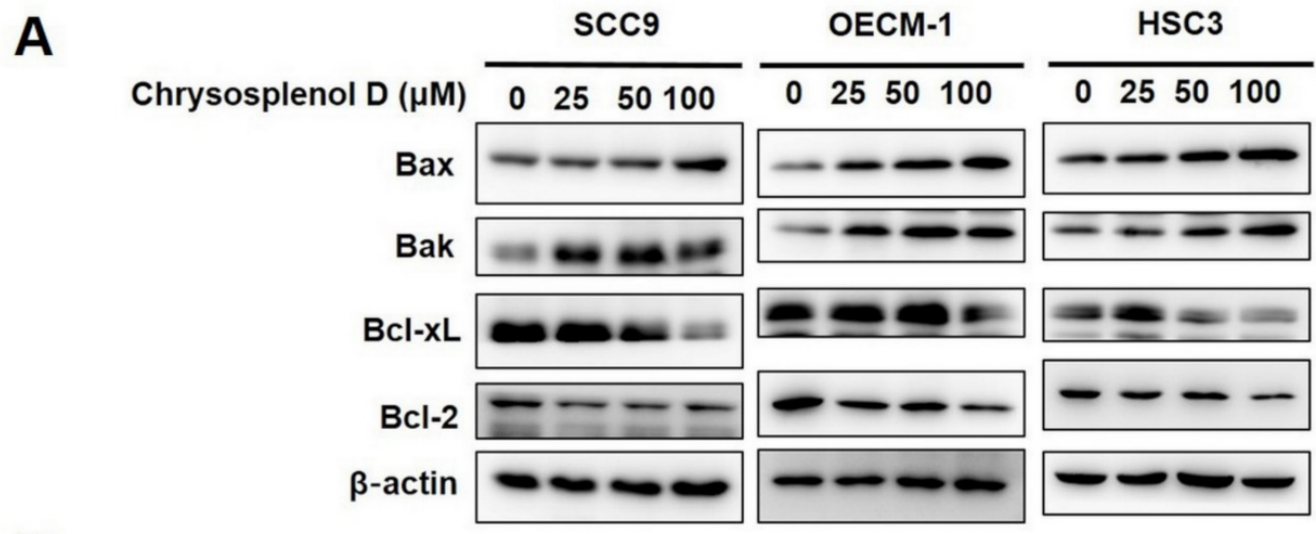

B

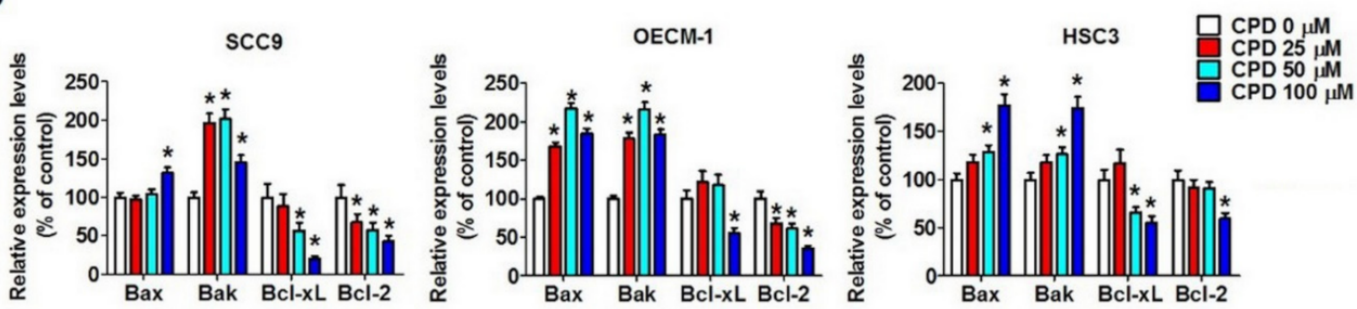

C

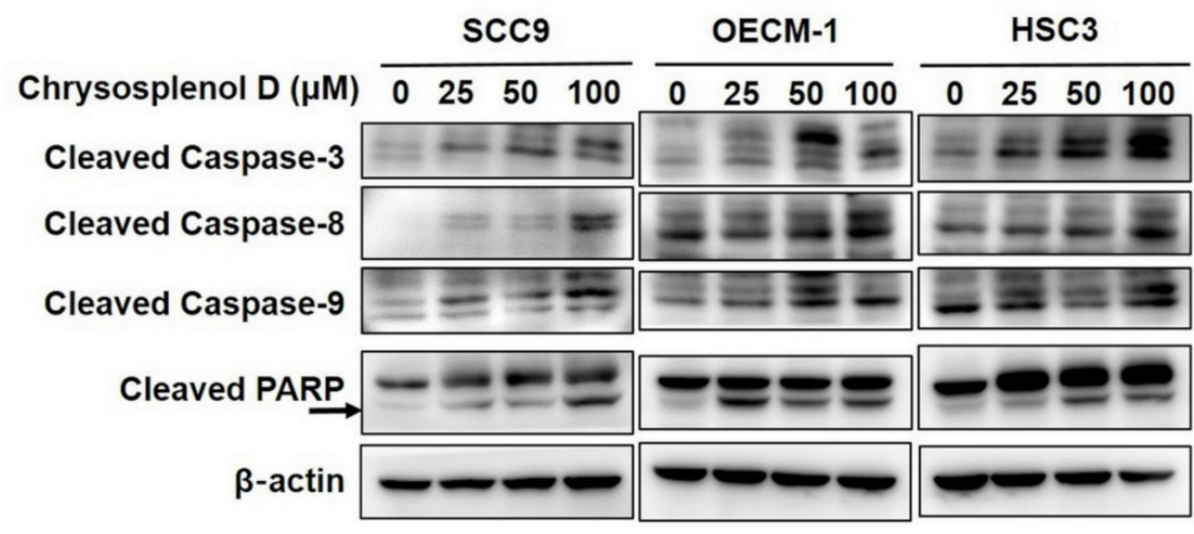

D

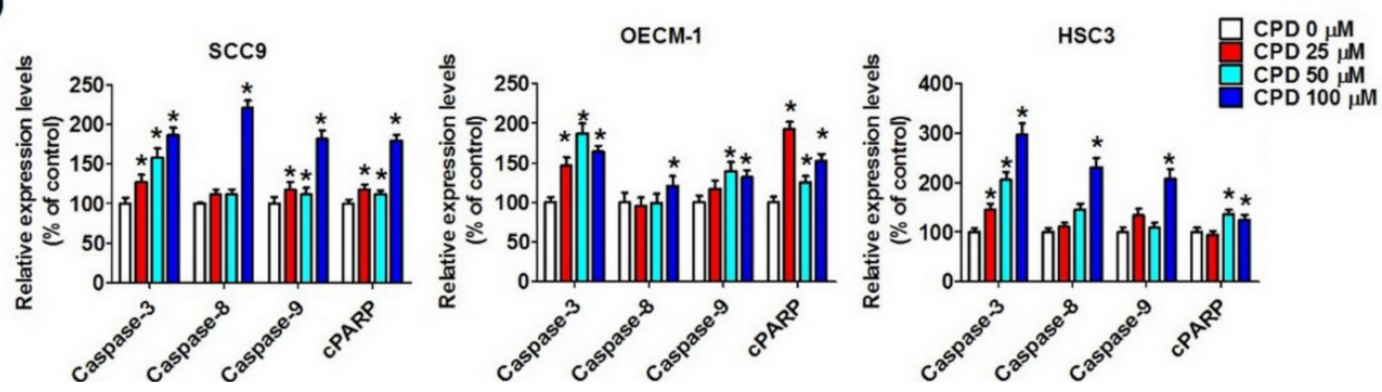

Figure 5. Chrysosplenol D induced apoptosis by regulating apoptotic-related proteins in OSCC cell lines. (A,B) Proapoptotic (Bax and Bak) and antiapoptotic proteins (Bcl-2 and Bcl-xL) were measured after chrysosplenol D treatment. The $\beta$-actin protein level was used to adjust the quantitative results of pro- and anti-apoptotic protein levels. Graphs show the findings of the statistical analysis of pro- and anti-apoptotic proteins. (C,D) The active forms of proteases (caspase-3, -8 , and -9) and poly (ADP-ribose) polymerase (PARP) in apoptotic regulation were measured through Western blot analysis. The $\beta$-actin protein level was used to adjust quantitative results. Graphs show the findings of the statistical analysis of apoptotic-regulating proteins. Data are presented as the mean \pm SD from three independent experiments ${ }^{*} p<0.05$ compared with the vehicle treatment group. 


\subsection{Activation of Autophagy and the Mitogen-Activated Protein Kinase (MAPK) Pathway by Chrysosplenol D in OSCC}

Studies have indicated that compounds that exert apoptotic effects may also activate autophagy $[45,46]$. Hence, we examined the autophagy-associated phenomenon and protein expression in chrysosplenol D-treated OSCC cell lines. As shown in Figure 6A, microtubule-associated protein 1A/1B-light chain 3 (hereafter referred to as LC3), which accumulates in autophagosomes and autolysosomes, was first examined through fluorescence microscopy. We observed that LC3 fluorescent puncta increased in a dose-dependent manner in chrysosplenol D-treated cells, and this increase was 2-3-fold higher than that in vehicle-treated cells (Figure 6B). Subsequently, we examined the formation of autophagosomes by using a cell meter autophagy assay kit. The fluorescence levels were increased in SCC-9, OECM-1, and HSC-3 cells (Figure 6C). Moreover, after chrysosplenol D treatment, the protein expression of LC3-I/II, Beclin-1, and Atg5-Atg12 complex increased, whereas that of p62/SQSTM1 decreased (Figure 6D,E).

The MAPK and PI3K/AKT pathways, which communicate signals from cell surface receptors to DNA present inside the nucleus, are involved in various cellular processes such as proliferation, apoptosis, stress responses, and differentiation [47]. To investigate the molecular mechanism of chrysosplenol D in OSCC cell lines, we analyzed the protein expression of MAPK proteins by performing Western blot analysis. As shown in Figure 7A, the active forms of phosphorylated AKT, p38, ERK1/2, and JNK1/2 were downregulated after chrysosplenol D treatment in SCC-9, OECM-1, and HSC-3 cell lines. Moreover, after chrysosplenol D treatment, the expression of phosphorylated AKT was the lowest in OECM-1 cells, whereas that of phosphorylated ERK1/2 was the lowest in HSC-3 cells (Figure 7B).

We used the PI3K/AKT inhibitor LY294002 and MAPK pathway inhibitors, namely SP600125 (JNK inhibitor), U0126 (ERK inhibitor), and SB203580 (p38 inhibitor), to investigate the relationship among chrysosplenol D-activated autophagy, apoptosis, and PI3K/AKT and MAPK signaling pathways. As shown in Figure 7C,E,G,I, cleaved PARP and LC3-I/II were the biomarkers of apoptosis and autophagy, respectively. Our results revealed that the inhibition of not only PI3K/AKT but also p38, ERK, and JNK in the three OSCC cell lines considerably enhanced chrysosplenol D-induced cleaved PARP activation (Figure 7D,F,H,J). However, the protein expression of LC3-I/II exhibited less or no difference between chrysosplenol D-treated cells and co-treated cells, indicating that chrysosplenol D might not regulate LC3-I/II expression through either the PI3K/AKT or MAPK pathway. The aforementioned results suggest that chrysosplenol D induced cleaved PARP-mediated apoptosis through PI3K/AKT and MAPK (ERK, JNK, and p38) signaling cascades in OSCC. 

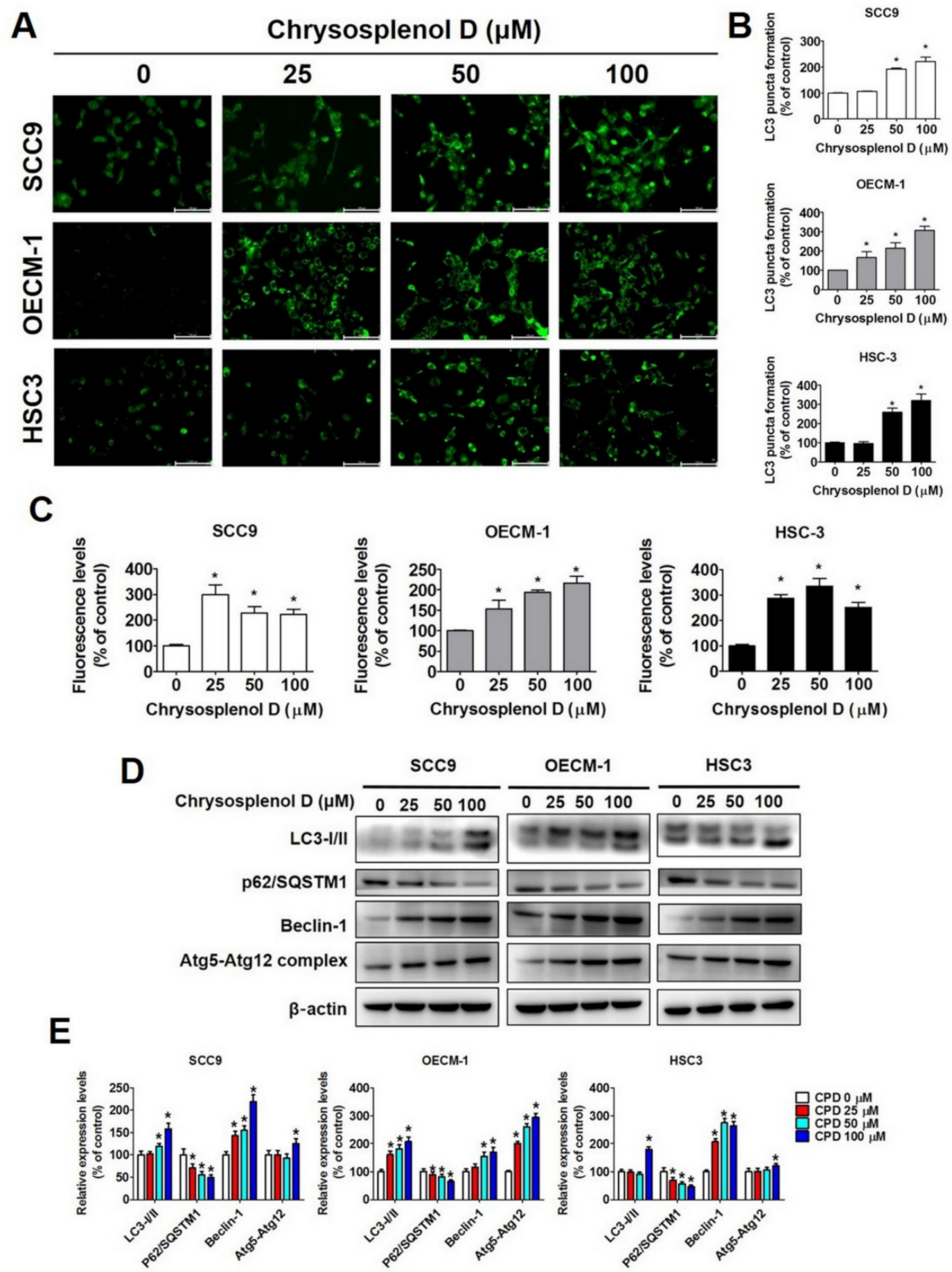

Figure 6. Autophagy induction by chrysosplenol D in OSCC cell lines. (A,B) SCC-9, OECM-1, and HSC-3 cells were treated with chrysosplenol D for $24 \mathrm{~h}$, followed by immunostaining and the observation of LC-3 under a fluorescence microscope at a magnification of $200 \times$. Graphs show the findings of the statistical analysis of LC-3 formation. (C) Chrysosplenol $\mathrm{D}$ induced the formation of autophagosomes in OSCC cells that was detected using a fluorescence microplate reader at Ex $/ \mathrm{Em}=485 / 530 \mathrm{~nm}$. (D,E) The protein expression of autophagic markers (LC3-I/II, p62/SQSTM1, Beclin-1, and Atg5-Atg12 complex) was measured through Western blot after chrysosplenol D treatment. The $\beta$-actin protein level was used to adjust quantitative results. Graphs show the findings of the statistical analysis of autophagy-related proteins. Data are presented as the mean $\pm \mathrm{SD}$ from three independent experiments ${ }^{*} p<0.05$ compared with the vehicle treatment group. 
A

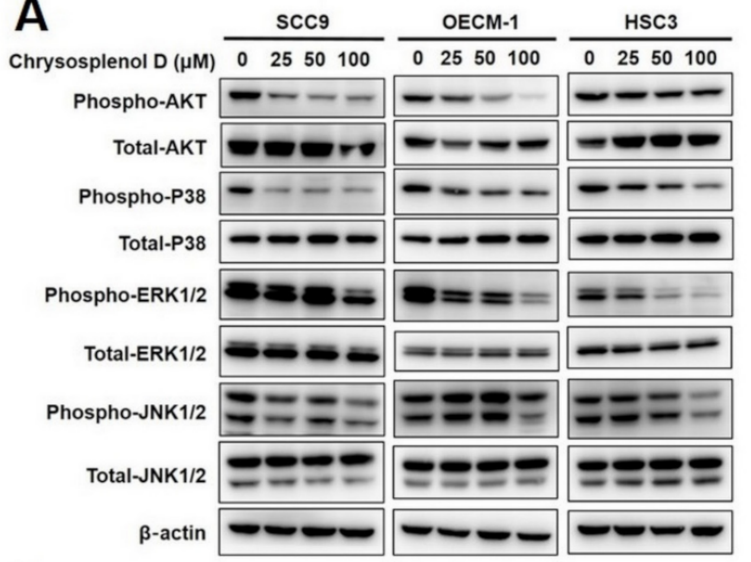

C

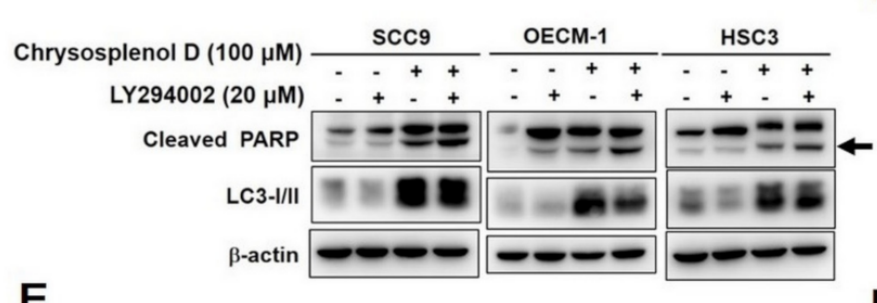

$E$

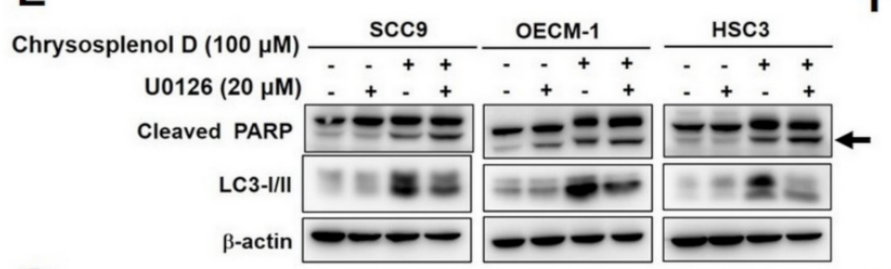

G
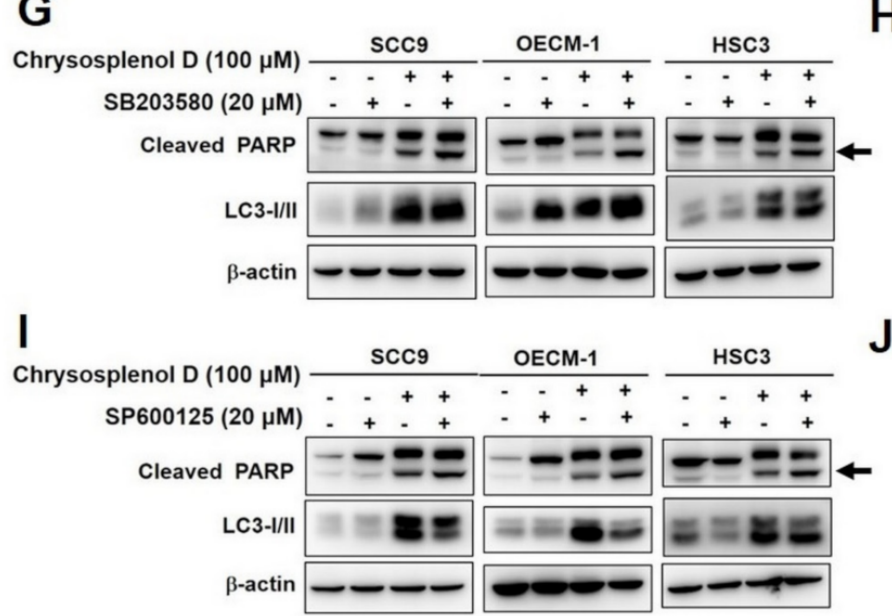

B

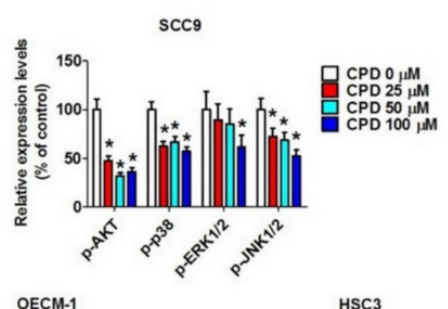

D

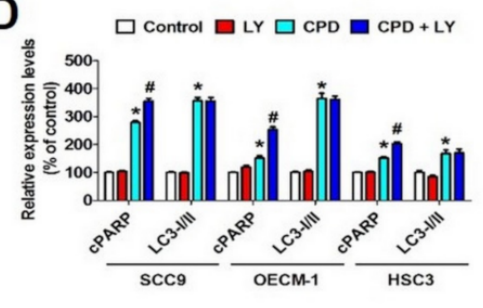

$\mathbf{F}$

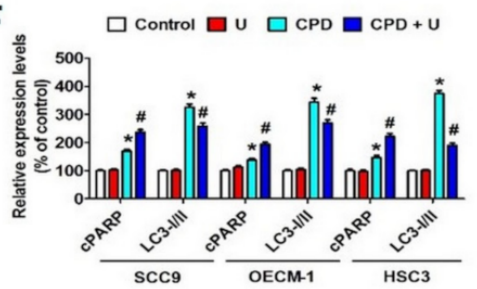

H
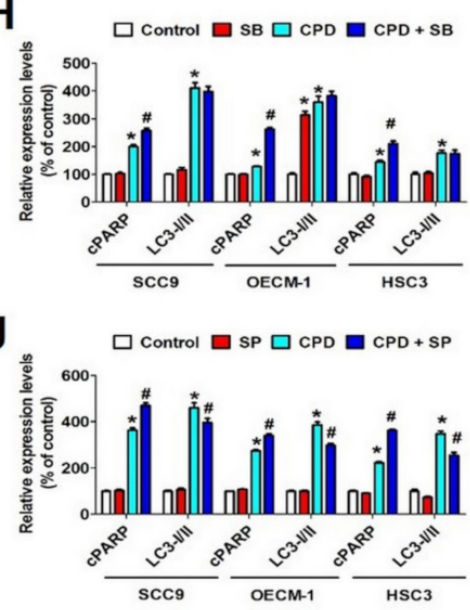

Figure 7. Chrysosplenol D regulated cell apoptosis through the PI3K/AKT and MAPK pathways. (A,B) After treatment with chrysosplenol D $(0,25,50$, and $100 \mu \mathrm{M})$ for $24 \mathrm{~h}$, OSCC cells were collected, and AKT and MAPK pathway proteins were detected using Western blot. The $\beta$-actin protein level was used to adjust quantitative results. Graphs show the findings of the statistical analysis of AKT and MAPK proteins. (C-J) SCC-9, OECM-1, and HSC-3 cells were pretreated with LY294002 $(20 \mu \mathrm{M})$, U0126 $(20 \mu \mathrm{M})$, SB203580 $(20 \mu \mathrm{M})$ or SP600125 $(20 \mu \mathrm{M})$ for $1 \mathrm{~h}$, followed by chrysosplenol D $(0$ and $100 \mu \mathrm{M}$ ) for another $24 \mathrm{~h}$. Western blot analysis was performed to detect the protein expression levels of cleaved PARP and LC3-I/II. The $\beta$-actin protein level was used to adjust quantitative results. Graphs show the findings of the statistical analysis of cleaved PARP and LC3-I/II proteins. Data are presented as the mean \pm SD from three independent experiments ${ }^{*} p<0.05$ compared with the vehicle treatment group. $\# p<0.05$ compared with chrysosplenol D treatment group. 


\subsection{HO-1 Is Involved in Chrysosplenol D-Activated Apoptotic Cell Death in OSCC}

Although HO- 1 is regarded as a predictive biomarker for several cancers [23,48], the role of HO-1 in OSCC remains unclear. To examine whether HO-1 regulates chrysosplenol D-activated apoptosis, we first analyzed the HO-1 protein level in chrysosplenol D-treated OSCC cell lines. The expression level of HO-1 was significantly increased after chrysosplenol D treatment in SCC-9, OECM-1, and HSC-3 cells (Figure 8A,B). Subsequently, we used HO-1-specific siRNA to knock down HO-1 combined with or without treatment with a high dose of chrysosplenol D $(100 \mu \mathrm{M})$. We observed that HO-1-specific siRNA significantly reversed chrysosplenol D-induced HO-1 protein expression (Figure 8C,D). However, the expression of chrysosplenol D-activated cleaved PARP decreased in the HO-1 siRNA-transfected group than in the control siRNA group (Figure 8E,F). In addition, the decrease in the viability of OSCC cell lines after chrysosplenol D treatment was reversed in the HO-1 siRNA-transfected group than in the control siRNA group (Figure 8G). We analyzed the gene expression of HO-1 (HMOX-1) in head and neck cancer tissues from the TCGA database and found a significantly lower HMOX1 expression in tumors tissues than in normal tissues (Figure 8H). Furthermore, in 43 paired tumor samples and normal adjacent tissue samples analyzed from the TCGA database, HMOX1 expression was lower in tumor samples than in normal adjacent tissue samples (Figure 8I). In addition, HMOX1 expression was higher in normal tissues than in tumor tissues in the GEO database (GSE3524; Figure 8J). Overall, these results suggest that increased HO-1 expression might be crucial for chrysosplenol D-induced apoptotic cell death, and the HO-1 expression level might be a biomarker for head and neck tumors. 


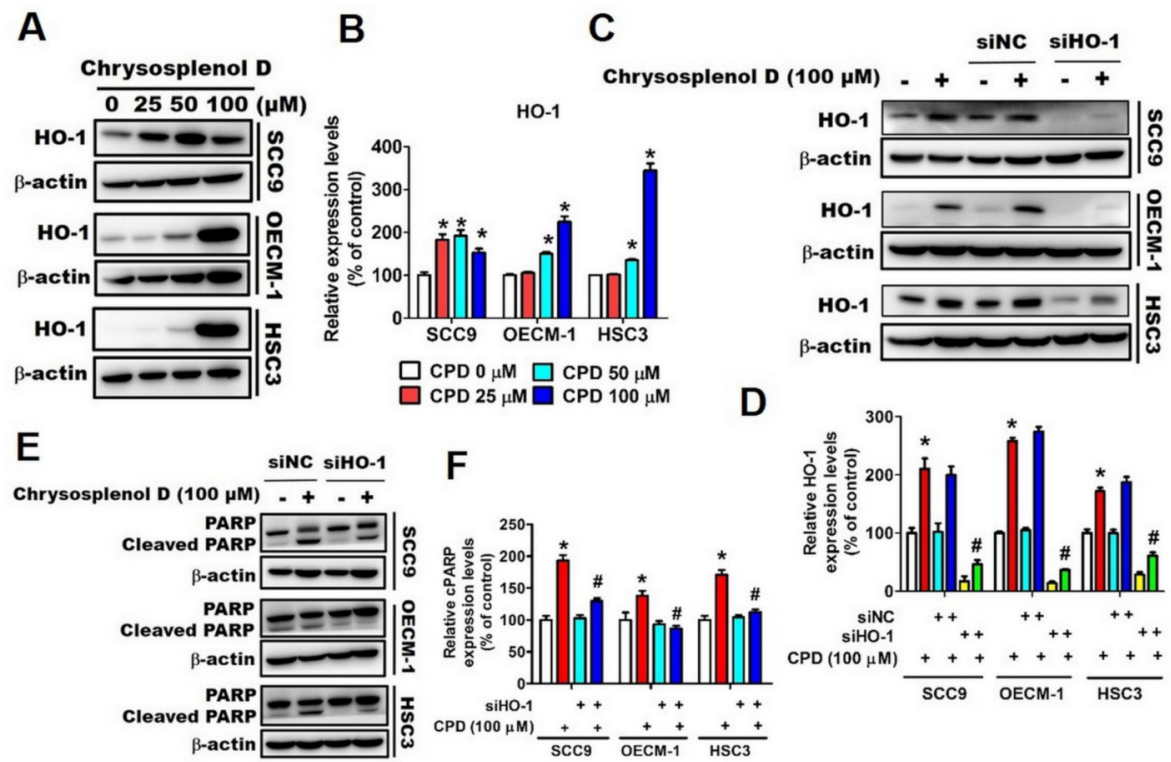

G
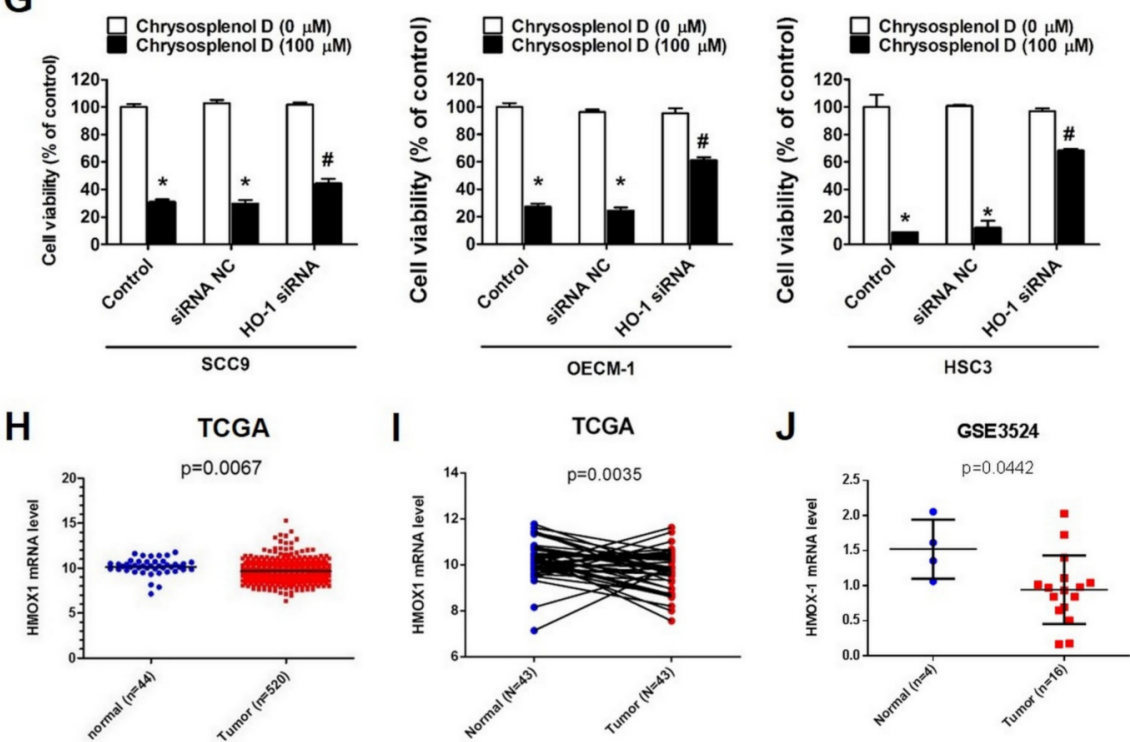

Figure 8. Heme oxygenase-1 plays a crucial rule in chrysosplenol D-induced anti-proliferation and PARP activation. (A,B) OSCC cells were treated with the indicated doses of chrysosplenol D $(0,25,50$, and $100 \mu \mathrm{M})$, and the HO- 1 expression level was detected through Western blot analysis. The $\beta$-actin protein level was used to adjust quantitative results. Graphs show the findings of the statistical analysis of HO-1 proteins. (C-G) SCC-9, OECM-1, and HSC-3 cells were transiently transfected with control siRNA or HO-1-specific siRNA and subjected to Western blot analysis and cell viability assay. (C,D) The knockdown efficiency of HO-1-specific siRNA and the combined effect of HO-1 siRNA and chrysosplenol D were determined by the expression of HO-1. The $\beta$-actin protein level was used to adjust quantitative results. Graphs show the findings of the statistical analysis of HO-1 protein. (E,F) OSCC cells were co-treated with HO-1-specific siRNA and chrysosplenol D, and the PARP expression level was analyzed using Western blot. The $\beta$-actin protein level was used to adjust quantitative results. Graphs show the findings of the statistical analysis of PARP protein. (G) OSCC cells were co-treated with HO-1-specific siRNA and chrysosplenol D, and cell viability was analyzed using the MTT assay. Data are presented as the mean \pm SD from three independent experiments ${ }^{*} p<0.05$ compared with the vehicle treatment group. $\# p<0.05$ compared with chrysosplenol D treatment group. (H) The HMOX1 mRNA level was analyzed from the head and neck squamous cell carcinoma (HNSCC) dataset, which was retrieved from The Cancer Genome Atlas (TCGA) database, for normal tissues $(n=44)$ and tumor tissues $(n=520)$. (I) The HMOX1 mRNA level in 43 paired cancer tissue samples and normal adjacent tissue samples from the TCGA database. (J) The HMOX1 mRNA expression level of patients with OSCC was analyzed from the Gene Expression Omnibus (GEO) dataset (GSE3524). 


\section{Discussion}

Chrysosplenol D is a flavonol isolated from $A$ annua L., a widely used traditional Chinese medicine. Few studies have examined the anticancer effects of chrysosplenol D on leukemia cells and triple-negative breast cancer cells [32,49]. However, its anticancer potential and molecular mechanisms should be extensively investigated. In this study, we observed that chrysosplenol D induced apoptosis in OSCC cell lines through $\mathrm{G}_{2} / \mathrm{M}$ phase arrest, chromatin condensation, changes in mitochondrial membrane potential, and extrinsic/intrinsic pathway regulation. In addition, chrysosplenol D treatment induced autophagy in OSCC cell lines. Moreover, increased AKT, JNK, ERK, and p38 expression might be major signaling pathways involved in the induction of apoptosis by chrysosplenol D. In addition, increased HO-1 expression was found to be critical for chrysosplenol Dinduced apoptosis.

Apoptotic induction in cancer cells has been widely applied in cancer therapy (e.g., the use of chemotherapeutic agents such as paclitaxel and doxorubicin) [50]. However, most chemotherapeutic agents exert cytotoxic effects on both cancer and normal cells, thus causing intolerable side effects in patients undergoing chemotherapy. Chrysosplenol D exhibited considerably lower cytotoxicity in peripheral blood mononuclear cells and normal breast epithelial cells than in cancer cells, indicating the selectivity of this flavonol for cancer cells [32]. This is the first study to demonstrate the anti-proliferative effect of chrysosplenol D on OSCC cell lines by performing cell viability and colony formation assays. On the basis of the findings of these assays, we further investigated the potential molecular mechanisms of this compound.

Uncontrolled proliferation is strongly correlated with cell cycle dysregulation in tumor cells [51]. The $\mathrm{G}_{2} / \mathrm{M}$ phase is one of the most prominent checkpoints in the cell cycle that is controlled by cyclin $\mathrm{B} / \mathrm{CDC} 2$ [52]. Our findings revealed that chrysosplenol $\mathrm{D}$ treatment increased cell cycle distribution in the $\mathrm{G}_{2} / \mathrm{M}$ phase in OSCC cell lines with a decreased expression of cyclin B. This finding is in accordance with the effect of chrysosplenol D on $\mathrm{G}_{2} / \mathrm{M}$ cell cycle arrest in previous studies [32,49]. In addition, we observed an increased expression of the CDK inhibitors p21 and p27, the two crucial cell cycle regulators, in chrysosplenol D-treated OSCC cell lines. A previous study reported that the expression of p21 and p27 inhibits not only mammalian cell proliferation but also cyclin-CDK complexes $[53,54]$. These findings indicate that chrysosplenol $\mathrm{D}$ might regulate the cell cycle in OSCC cell lines by directly inhibiting cell cycle-related proteins and disrupting the cyclinCDK connection through the upregulation of p21 expression. We observed decreased levels of cyclin D3, cyclin E2, CDK2, CDK4, and CDK6 in chrysosplenol D-treated cells, and this decrease was correlated with $\mathrm{G}_{0} / \mathrm{G}_{1}$ and $\mathrm{S}$ phases [55]. However, future studies should investigate the regulation of cell cycle transition.

Chromatin condensation is the most characteristic feature of apoptosis [56] and can be used to observe the apoptotic effect of anticancer compounds [45,57]. In addition, apoptosis can be examined by detecting mitochondrial membrane potential through JC-1 staining and plasma membrane integrity and permeability through annexin V/PI staining $[56,58]$. Our results revealed that chrysosplenol D treatment increased chromatin condensation, apoptotic cell number, and depolarized mitochondrial level in OSCC cell lines, indicating the induction of apoptosis by chrysosplenol D.

Extrinsic and intrinsic pathways are major signaling pathways that initiate intracellular apoptosis. The extrinsic pathway involves death receptor-mediated interaction, whereas the intrinsic pathway involves non-receptor-mediated stimuli. The initiation of the tumor necrosis factor (TNF)-related apoptosis-inducing ligand (TRAIL)/DR4/DR5 signaling pathway can drive adaptor proteins, namely Fas-associated death receptor and TRADD, thus recruiting and activating caspase-8 [59]. Activated caspase- 8 can cleave the proapoptotic Bcl-2 family member Bid. Furthermore, truncated Bid can localize to mitochondria and interact with Bax and Bak to promote the release of cytochrome c, thus providing a mechanistic link between the intrinsic and extrinsic pathways [60]. We found that chrysosplenol D induced the expression of DR5 and DcR2 in OSCC cell lines. Decoy 
receptors, such as, DcR1, DcR2, and osteoprotegerin, lack the functional death domain, thus preventing the induction of apoptosis and the binding of TRAIL to DRs [61]. DcR may compete with agonistic receptors, such as DR4 and DR5, for TRAIL binding [62]. Furthermore, the expression of cleaved caspase-8, Bak, and Bax and downstream apoptotic molecules, including cleaved caspase- 3 and -9 and PARP, increased after chrysosplenol $\mathrm{D}$ treatment. These findings indicate that the affinity of DcR2 to TRAIL may be lower than that of agonistic DR5 to active apoptotic processes in chrysosplenol D-treated OSCC cell lines.

Autophagy begins with the formation of phagophores (also called isolation membranes) that contain the lipid kinase vacuolar protein sorting 34-Beclin-1 complex on the membrane. This complex is usually inactivated by antiapoptotic proteins from the Bcl-2 family including Bcl-2 and Bcl-xL [63]. Gump and Thorburn demonstrated that apoptosis and autophagy are related through two autophagy proteins, namely p62 and Beclin-1 [64]. P62 not only acts as an autophagic degradation protein but also directly interacts with apoptotic proteins such as caspase-8, ERK, and TNF receptor-associated factor $6[65,66]$. During the formation of autophagosomes and autolysosomes, LC3 is conjugated on the membrane and, therefore, regarded as the marker of autophagic process activation [67]. During the early steps of the formation of autophagosomes, ATG5, ATG12, and ATG16L1 form a complex termed as the autophagy elongation complex (ATG5-12/16L1). This elongation complex is necessary to determine the site of LC3 on the autophagosomal membrane [68]. In accordance with the finding of a previous study [32], our results revealed that chrysosplenol D promoted the formation of autophagosomes in a dose-dependent manner and regulated autophagic proteins, namely p62, Beclin-1, LC3, and Atg5-Atg12 complex.

$\mathrm{PI} 3 \mathrm{~K} / \mathrm{AKT}$ and MAPK signaling pathways regulate various biological processes in mammalian cells through cellular mechanisms and play critical roles in tumorigenesis $[69,70]$. However, the results of the co-treatment of chrysosplenol D and MAPK inhibitors indicated that chrysosplenol D might not regulate LC3 protein through these signaling pathways. Hence, the mechanism through which chrysosplenol D regulates autophagy should be investigated in future studies.

Anticancer compounds exert their effects on OSCC cell lines through the PI3K/AKT and MAPK signaling pathways. For instance, norcantharidin, a demethylated analog of cantharidin, activates apoptosis by triggering the p38 MAPK pathway in OSCC [71], as well as activates aglycone and genipin and suppresses OSCC growth through the $\mathrm{PI} 3 \mathrm{~K} / \mathrm{AKT} / \mathrm{mTOR}$ pathway [72]. Our previous study demonstrated that dehydrocrenatidine, a natural alkaloid, modulates OSCC cell apoptosis through both JNK and ERK MAPK signaling pathways [73]. Furthermore, chrysosplenol D could induce apoptosis through the ERK signaling pathway in triple-negative human breast cancer cells [32]; this finding is consistent with our results. Moreover, chrysosplenol D activated the expression of cleaved PARP through not only the ERK pathway but through the p38, JNK, and PI3K/AKT signaling pathway. The findings of the present study provide new insights into mechanisms through which chrysosplenol D regulates cellular signaling pathways in OSCC.

HO-1 is a stress-inducible enzyme that exerts cytoprotective effects against stressrelated conditions. However, accumulating evidence has suggested that HO-1 plays a specific role in cancer progression, including in cell metastasis, angiogenesis, and proliferation [74]. The effect of HO-1 widely varies among different cancer types. For instance, in pancreatic cancer, HO- 1 accelerated tumor angiogenesis, whereas low $\mathrm{HO}-1$ increased tumor responsiveness to anticancer treatment $[75,76]$. In breast cancer, $\mathrm{HO}-1$ overexpression showed a correlation with decreasing tumor volume in vivo and prolonged patient survival [27]. Furthermore, HO-1 was reported to be correlated with lymph node metastasis in patients with tongue squamous cell carcinoma [28]. HO-1 mediated cadmium-induced autophagy/apoptosis in OSCC [77]. Chien et al. found that demethoxycurcumin caused cell apoptosis by triggering $\mathrm{HO}-1$ and the inhibitor of apoptosis proteins (IAPs) such as cellular IAP1 and X-linked IAP [78]. Therefore, we investigated the role of HO-1 in chrysosplenol D-mediated apoptosis in OSCC. We observed that chrysosplenol D caused HO-1 
upregulation and subsequently promoted PARP-dependent apoptosis. The clinical data from the TCGA and GEO databases are consistent with our finding that the HO-1 expression level was higher in normal oral tissues or adjacent normal tissues than in OSCC tumor tissues. Although the relationship of chrysosplenol D with HO-1 and MAPK signaling pathways has been observed in OSCC, the effect of chrysosplenol D on OSCC should be thoroughly explored.

\section{Conclusions}

Our results suggest that chrysosplenol D might be a potential anticancer agent for treating OSCC.

Author Contributions: Conceptualization, M.-J.H. and M.-K.C.; methodology, H.-Y.H., Y.-S.L., C.C.L., Y.-C.C.; software, H.-Y.H., Y.-S.L., C.-C.L., Y.-C.C.; writing-original draft preparation, M.-J.H. and H.-Y.H.; writing-review and editing, M.-J.H. and M.-K.C. All authors have read and agreed to the published version of the manuscript.

Funding: This research received no external funding.

Institutional Review Board Statement: Not applicable.

Informed Consent Statement: Not applicable.

Data Availability Statement: The study did not report any data.

Acknowledgments: This study was supported by grants from National Science Council, Taiwan (MOST 109-2314-B-371-004-MY3; 110-2314-B-371-006). The authors of the manuscript do not have a direct financial relation with the commercial entity mentioned in this paper.

Conflicts of Interest: The authors declare no conflict of interest.

\section{References}

1. Xiao, H.; Langerman, A.; Zhang, Y.; Khalid, O.; Hu, S.; Cao, C.X.; Lingen, M.W.; Wong, D.T.W. Quantitative proteomic analysis of microdissected oral epithelium for cancer biomarker discovery. Oral Oncol. 2015, 51, 1011-1019. [CrossRef]

2. Sung, H.; Ferlay, J.; Siegel, R.L.; Laversanne, M.; Soerjomataram, I.; Jemal, A.; Bray, F. Global cancer statistics 2020: GLOBOCAN estimates of incidence and mortality worldwide for 36 cancers in 185 countries. CA Cancer J. Clin. 2021, 71, 209-249. [CrossRef] [PubMed]

3. Gupta, S.; Gupta, R.; Sinha, D.N.; Mehrotra, R. Relationship between type of smokeless tobacco \& risk of cancer: A systematic review. Indian J. Med. Res. 2018, 148, 56-76. [CrossRef]

4. Lambert, R.; Sauvaget, C.; de Camargo Cancela, M.; Sankaranarayanan, R. Epidemiology of cancer from the oral cavity and oropharynx. Eur. J. Gastroenterol. Hepatol. 2011, 23, 633-641. [CrossRef] [PubMed]

5. Liu, T.; David, M.; Ellis, O.; Hubert Low, T.H.; Palme, C.E.; Clark, J.; Batstone, M. Treatment for oral squamous cell carcinoma: Impact of surgeon volume on survival. Oral Oncol. 2019, 96, 60-65. [CrossRef]

6. Gharat, S.A.; Momin, M.; Bhavsar, C. Oral Squamous Cell Carcinoma: Current Treatment Strategies and Nanotechnology-Based Approaches for Prevention and Therapy. Crit. Rev. Ther. Drug Carr. Syst. 2016, 33, 363-400. [CrossRef]

7. Sim, Y.C.; Hwang, J.H.; Ahn, K.M. Overall and disease-specific survival outcomes following primary surgery for oral squamous cell carcinoma: Analysis of consecutive 67 patients. J. Korean Assoc. Oral Maxillofac. Surg. 2019, 45, 83-90. [CrossRef]

8. Choi, A.M.; Ryter, S.W.; Levine, B. Autophagy in human health and disease. N. Engl. J. Med. 2013, 368, 1845-1846. [CrossRef] [PubMed]

9. Mizushima, N.; Noda, T.; Yoshimori, T.; Tanaka, Y.; Ishii, T.; George, M.D.; Klionsky, D.J;; Ohsumi, M.; Ohsumi, Y. A protein conjugation system essential for autophagy. Nature 1998, 395, 395-398. [CrossRef]

10. Oberhammer, F.A.; Hochegger, K.; Froschl, G.; Tiefenbacher, R.; Pavelka, M. Chromatin condensation during apoptosis is accompanied by degradation of lamin A+B, without enhanced activation of cdc2 kinase. J. Cell Biol. 1994, 126, 827-837. [CrossRef]

11. Xu, X.; Lai, Y.; Hua, Z.C. Apoptosis and apoptotic body: Disease message and therapeutic target potentials. Biosci. Rep. 2019, 39, BSR20180992. [CrossRef] [PubMed]

12. Chipuk, J.E.; Bouchier-Hayes, L.; Green, D.R. Mitochondrial outer membrane permeabilization during apoptosis: The innocent bystander scenario. Cell Death Differ. 2006, 13, 1396-1402. [CrossRef] [PubMed]

13. Li, J.; Yuan, J. Caspases in apoptosis and beyond. Oncogene 2008, 27, 6194-6206. [CrossRef]

14. Lowe, S.W.; Lin, A.W. Apoptosis in cancer. Carcinogenesis 2000, 21, 485-495. [CrossRef] [PubMed]

15. Liu, E.Y.; Ryan, K.M. Autophagy and cancer-Issues we need to digest. J. Cell Sci. 2012, 125, 2349-2358. [CrossRef]

16. Jin, S. Autophagy, mitochondrial quality control, and oncogenesis. Autophagy 2006, 2, 80-84. [CrossRef] [PubMed]

17. Karantza-Wadsworth, V.; White, E. Role of autophagy in breast cancer. Autophagy 2007, 3, 610-613. [CrossRef] [PubMed] 
18. Jin, S.; White, E. Role of autophagy in cancer: Management of metabolic stress. Autophagy 2007, 3, 28-31. [CrossRef]

19. Graeber, T.G.; Osmanian, C.; Jacks, T.; Housman, D.E.; Koch, C.J.; Lowe, S.W.; Giaccia, A.J. Hypoxia-mediated selection of cells with diminished apoptotic potential in solid tumours. Nature 1996, 379, 88-91. [CrossRef]

20. Degenhardt, K.; Mathew, R.; Beaudoin, B.; Bray, K.; Anderson, D.; Chen, G.; Mukherjee, C.; Shi, Y.; Gelinas, C.; Fan, Y.; et al. Autophagy promotes tumor cell survival and restricts necrosis, inflammation, and tumorigenesis. Cancer Cell 2006, 10, 51-64. [CrossRef]

21. Fulda, S.; Debatin, K.M. Extrinsic versus intrinsic apoptosis pathways in anticancer chemotherapy. Oncogene 2006, $25,4798-4811$. [CrossRef]

22. Ashkenazi, A. Targeting the extrinsic apoptosis pathway in cancer. Cytokine Growth Factor Rev. 2008, 19, 325-331. [CrossRef]

23. Chau, L.Y. Heme oxygenase-1: Emerging target of cancer therapy. J. Biomed. Sci. 2015, 22, 22. [CrossRef] [PubMed]

24. Yin, Y.; Liu, Q.; Wang, B.; Chen, G.; Xu, L.; Zhou, H. Expression and function of heme oxygenase-1 in human gastric cancer. Exp. Biol. Med. (Maywood) 2012, 237, 362-371. [CrossRef] [PubMed]

25. Degese, M.S.; Mendizabal, J.E.; Gandini, N.A.; Gutkind, J.S.; Molinolo, A.; Hewitt, S.M.; Curino, A.C.; Coso, O.A.; Facchinetti, M.M. Expression of heme oxygenase-1 in non-small cell lung cancer (NSCLC) and its correlation with clinical data. Lung Cancer 2012, 77, 168-175. [CrossRef]

26. Hsu, F.F.; Yeh, C.T.; Sun, Y.J.; Chiang, M.T.; Lan, W.M.; Li, F.A.; Lee, W.H.; Chau, L.Y. Signal peptide peptidase-mediated nuclear localization of heme oxygenase-1 promotes cancer cell proliferation and invasion independent of its enzymatic activity. Oncogene 2015, 34, 2410-2411. [CrossRef]

27. Gandini, N.A.; Alonso, E.N.; Fermento, M.E.; Mascaro, M.; Abba, M.C.; Colo, G.P.; Arevalo, J.; Ferronato, M.J.; Guevara, J.A.; Nunez, M.; et al. Heme Oxygenase-1 Has an Antitumor Role in Breast Cancer. Antioxid. Redox Signal. 2019, 30, $2030-2049$. [CrossRef] [PubMed]

28. Yanagawa, T.; Omura, K.; Harada, H.; Nakaso, K.; Iwasa, S.; Koyama, Y.; Onizawa, K.; Yusa, H.; Yoshida, H. Heme oxygenase-1 expression predicts cervical lymph node metastasis of tongue squamous cell carcinomas. Oral Oncol. 2004, 40, 21-27. [CrossRef]

29. Bridgford, J.L.; Xie, S.C.; Cobbold, S.A.; Pasaje, C.F.A.; Herrmann, S.; Yang, T.; Gillett, D.L.; Dick, L.R.; Ralph, S.A.; Dogovski, C.; et al. Artemisinin kills malaria parasites by damaging proteins and inhibiting the proteasome. Nat. Commun. $2018,9,3801$. [CrossRef]

30. Slezakova, S.; Ruda-Kucerova, J. Anticancer Activity of Artemisinin and its Derivatives. Anticancer Res. 2017, 37, 5995-6003. [CrossRef]

31. Ferreira, J.F.; Luthria, D.L.; Sasaki, T.; Heyerick, A. Flavonoids from Artemisia annua L. as antioxidants and their potential synergism with artemisinin against malaria and cancer. Molecules 2010, 15, 3135-3170. [CrossRef] [PubMed]

32. Lang, S.J.; Schmiech, M.; Hafner, S.; Paetz, C.; Werner, K.; El Gaafary, M.; Schmidt, C.Q.; Syrovets, T.; Simmet, T. Chrysosplenol d, a Flavonol from Artemisia annua, Induces ERK1/2-Mediated Apoptosis in Triple Negative Human Breast Cancer Cells. Int. J. Mol. Sci. 2020, 21, 4090. [CrossRef]

33. Li, Y.J.; Guo, Y.; Yang, Q.; Weng, X.G.; Yang, L.; Wang, Y.J.; Chen, Y.; Zhang, D.; Li, Q.; Liu, X.C.; et al. Flavonoids casticin and chrysosplenol D from Artemisia annua L. inhibit inflammation in vitro and in vivo. Toxicol. Appl. Pharmacol. 2015, 286, 151-158. [CrossRef]

34. Duo, J.; Ying, G.G.; Wang, G.W.; Zhang, L. Quercetin inhibits human breast cancer cell proliferation and induces apoptosis via Bcl-2 and Bax regulation. Mol. Med. Rep. 2012, 5, 1453-1456. [CrossRef]

35. Li, W.; Du, B.; Wang, T.; Wang, S.; Zhang, J. Kaempferol induces apoptosis in human HCT116 colon cancer cells via the AtaxiaTelangiectasia Mutated-p53 pathway with the involvement of p53 Upregulated Modulator of Apoptosis. Chem. Biol. Interact. 2009, 177, 121-127. [CrossRef]

36. Zhou, Y.; Peng, Y.; Mao, Q.Q.; Li, X.; Chen, M.W.; Su, J.; Tian, L.; Mao, N.Q.; Long, L.Z.; Quan, M.F.; et al. Casticin induces caspase-mediated apoptosis via activation of mitochondrial pathway and upregulation of DR5 in human lung cancer cells. Asian Pac. J. Trop. Med. 2013, 6, 372-378. [CrossRef]

37. Franken, N.A.; Rodermond, H.M.; Stap, J.; Haveman, J.; van Bree, C. Clonogenic assay of cells in vitro. Nat. Protoc. 2006, 1, 2315-2319. [CrossRef] [PubMed]

38. Mahmood, T.; Yang, P.C. Western blot: Technique, theory, and trouble shooting. N. Am. J. Med. Sci. 2012, 4, 429-434. [CrossRef] [PubMed]

39. Estandarte, A.K.; Botchway, S.; Lynch, C.; Yusuf, M.; Robinson, I. The use of DAPI fluorescence lifetime imaging for investigating chromatin condensation in human chromosomes. Sci. Rep. 2016, 6, 31417. [CrossRef]

40. Sakamuru, S.; Attene-Ramos, M.S.; Xia, M. Mitochondrial Membrane Potential Assay. Methods Mol. Biol. 2016, 1473, 17-22. [CrossRef]

41. Chen, J.C.; Hsieh, M.C.; Lin, S.H.; Lin, C.C.; Hsi, Y.T.; Lo, Y.S.; Chuang, Y.C.; Hsieh, M.J.; Chen, M.K. Coronarin D induces reactive oxygen species-mediated cell death in human nasopharyngeal cancer cells through inhibition of p38 MAPK and activation of JNK. Oncotarget 2017, 8, 108006-108019. [CrossRef]

42. Orhon, I.; Reggiori, F. Assays to Monitor Autophagy Progression in Cell Cultures. Cells 2017, 6, 20. [CrossRef]

43. Saraste, A.; Pulkki, K. Morphologic and biochemical hallmarks of apoptosis. Cardiovasc. Res. 2000, 45, 528-537. [CrossRef]

44. Ly, J.D.; Grubb, D.R.; Lawen, A. The mitochondrial membrane potential (deltapsi(m)) in apoptosis; an update. Apoptosis 2003, 8 , 115-128. [CrossRef] 
45. Chen, Y.T.; Hsieh, M.J.; Chen, P.N.; Weng, C.J.; Yang, S.F.; Lin, C.W. Erianin Induces Apoptosis and Autophagy in Oral Squamous Cell Carcinoma Cells. Am. J. Chin. Med. 2020, 48, 183-200. [CrossRef]

46. Zhu, Y.; Bu, S. Curcumin Induces Autophagy, Apoptosis, and Cell Cycle Arrest in Human Pancreatic Cancer Cells. Evid.-Based Complementary Alternat. Med. 2017, 2017, 5787218. [CrossRef]

47. Guo, Y.J.; Pan, W.W.; Liu, S.B.; Shen, Z.F.; Xu, Y.; Hu, L.L. ERK/MAPK signalling pathway and tumorigenesis. Exp. Ther. Med. 2020, 19, 1997-2007. [CrossRef]

48. Zheng, W.X.; Yan, F.; Xue, Q.; Wu, G.J.; Qin, W.J.; Wang, F.L.; Qin, J.; Tian, C.J.; Yuan, J.L. Heme oxygenase-1 is a predictive biomarker for therapeutic targeting of advanced clear cell renal cell carcinoma treated with sorafenib or sunitinib. OncoTargets Ther. 2015, 8, 2081-2088. [CrossRef]

49. Li, W.X.; Cui, C.B.; Cai, B.; Wang, H.Y.; Yao, X.S. Flavonoids from Vitex trifolia L. inhibit cell cycle progression at G2/M phase and induce apoptosis in mammalian cancer cells. J. Asian Nat. Prod. Res. 2005, 7, 615-626. [CrossRef] [PubMed]

50. Lee, H.H.; Ye, S.; Li, X.J.; Lee, K.B.; Park, M.H.; Kim, S.M. Combination treatment with paclitaxel and doxorubicin inhibits growth of human esophageal squamous cancer cells by inactivation of Akt. Oncol. Rep. 2014, 31, 183-188. [CrossRef] [PubMed]

51. Stewart, Z.A.; Westfall, M.D.; Pietenpol, J.A. Cell-cycle dysregulation and anticancer therapy. Trends Pharmacol. Sci. 2003, 24, 139-145. [CrossRef]

52. Asghar, U.; Witkiewicz, A.K.; Turner, N.C.; Knudsen, E.S. The history and future of targeting cyclin-dependent kinases in cancer therapy. Nat. Rev. Drug Discov. 2015, 14, 130-146. [CrossRef]

53. Xiong, Y.; Hannon, G.J.; Zhang, H.; Casso, D.; Kobayashi, R.; Beach, D. p21 is a universal inhibitor of cyclin kinases. Nature 1993, 366, 701-704. [CrossRef] [PubMed]

54. Russo, A.A.; Jeffrey, P.D.; Patten, A.K.; Massague, J.; Pavletich, N.P. Crystal structure of the p27Kip1 cyclin-dependent-kinase inhibitor bound to the cyclin A-Cdk2 complex. Nature 1996, 382, 325-331. [CrossRef] [PubMed]

55. Malumbres, M.; Barbacid, M. Cell cycle, CDKs and cancer: A changing paradigm. Nat. Rev. Cancer 2009, 9, 153-166. [CrossRef] [PubMed]

56. Elmore, S. Apoptosis: A review of programmed cell death. Toxicol. Pathol. 2007, 35, 495-516. [CrossRef] [PubMed]

57. Hsieh, M.J.; Wang, C.W.; Lin, J.T.; Chuang, Y.C.; Hsi, Y.T.; Lo, Y.S.; Lin, C.C.; Chen, M.K. Celastrol, a plant-derived triterpene, induces cisplatin-resistance nasopharyngeal carcinoma cancer cell apoptosis though ERK1/2 and p38 MAPK signaling pathway. Phytomedicine 2019, 58, 152805. [CrossRef]

58. Sivandzade, F.; Bhalerao, A.; Cucullo, L. Analysis of the Mitochondrial Membrane Potential Using the Cationic JC-1 Dye as a Sensitive Fluorescent Probe. Bio-Protocol 2019, 9, e3128. [CrossRef]

59. Wang, S.; El-Deiry, W.S. TRAIL and apoptosis induction by TNF-family death receptors. Oncogene 2003, 22, 8628-8633. [CrossRef]

60. Green, D.R. Apoptotic pathways: Paper wraps stone blunts scissors. Cell 2000, 102, 1-4. [CrossRef]

61. LeBlanc, H.N.; Ashkenazi, A. Apo2L/TRAIL and its death and decoy receptors. Cell Death Differ. 2003, 10, 66-75. [CrossRef]

62. Pan, G.; Ni, J.; Wei, Y.F.; Yu, G.; Gentz, R.; Dixit, V.M. An antagonist decoy receptor and a death domain-containing receptor for TRAIL. Science 1997, 277, 815-818. [CrossRef]

63. Pattingre, S.; Tassa, A.; Qu, X.; Garuti, R.; Liang, X.H.; Mizushima, N.; Packer, M.; Schneider, M.D.; Levine, B. Bcl-2 antiapoptotic proteins inhibit Beclin 1-dependent autophagy. Cell 2005, 122, 927-939. [CrossRef] [PubMed]

64. Gump, J.M.; Thorburn, A. Autophagy and apoptosis: What is the connection? Trends Cell Biol. 2011, 21, 387-392. [CrossRef] [PubMed]

65. Moscat, J.; Diaz-Meco, M.T. p62 at the crossroads of autophagy, apoptosis, and cancer. Cell 2009, 137, 1001-1004. [CrossRef]

66. Mathew, R.; Karp, C.M.; Beaudoin, B.; Vuong, N.; Chen, G.; Chen, H.Y.; Bray, K.; Reddy, A.; Bhanot, G.; Gelinas, C.; et al. Autophagy suppresses tumorigenesis through elimination of p62. Cell 2009, 137, 1062-1075. [CrossRef]

67. Marino, G.; Niso-Santano, M.; Baehrecke, E.H.; Kroemer, G. Self-consumption: The interplay of autophagy and apoptosis. Nat. Rev. Mol. Cell Biol. 2014, 15, 81-94. [CrossRef]

68. Fujita, N.; Itoh, T.; Omori, H.; Fukuda, M.; Noda, T.; Yoshimori, T. The Atg16L complex specifies the site of LC3 lipidation for membrane biogenesis in autophagy. Mol. Biol. Cell 2008, 19, 2092-2100. [CrossRef]

69. Dhillon, A.S.; Hagan, S.; Rath, O.; Kolch, W. MAP kinase signalling pathways in cancer. Oncogene 2007, 26, 3279-3290. [CrossRef] [PubMed]

70. Fresno Vara, J.A.; Casado, E.; de Castro, J.; Cejas, P.; Belda-Iniesta, C.; Gonzalez-Baron, M. PI3K/Akt signalling pathway and cancer. Cancer Treat. Rev. 2004, 30, 193-204. [CrossRef] [PubMed]

71. Ahn, C.H.; Hong, K.O.; Jin, B.; Lee, W.; Jung, Y.C.; Lee, H.; Shin, J.A.; Cho, S.D.; Hong, S.D. Contribution of p38 MAPK Pathway to Norcantharidin-Induced Programmed Cell Death in Human Oral Squamous Cell Carcinoma. Int. J. Mol. Sci. 2019, $20,3487$. [CrossRef] [PubMed]

72. Wei, M.; Wu, Y.; Liu, H.; Xie, C. Genipin Induces Autophagy and Suppresses Cell Growth of Oral Squamous Cell Carcinoma via PI3K/AKT/MTOR Pathway. Drug Des. Dev. Ther. 2020, 14, 395-405. [CrossRef]

73. Ho, H.Y.; Lin, C.C.; Chuang, Y.C.; Lo, Y.S.; Hsieh, M.J.; Chen, M.K. Apoptotic effects of dehydrocrenatidine via JNK and ERK pathway regulation in oral squamous cell carcinoma. Biomed. Pharmacother. 2021, 137, 111362. [CrossRef] [PubMed]

74. Nitti, M.; Piras, S.; Marinari, U.M.; Moretta, L.; Pronzato, M.A.; Furfaro, A.L. HO-1 Induction in Cancer Progression: A Matter of Cell Adaptation. Antioxidants 2017, 6, 29. [CrossRef] 
75. Sunamura, M.; Duda, D.G.; Ghattas, M.H.; Lozonschi, L.; Motoi, F.; Yamauchi, J.; Matsuno, S.; Shibahara, S.; Abraham, N.G. Heme oxygenase-1 accelerates tumor angiogenesis of human pancreatic cancer. Angiogenesis 2003, 6, 15-24. [CrossRef] [PubMed]

76. Berberat, P.O.; Dambrauskas, Z.; Gulbinas, A.; Giese, T.; Giese, N.; Kunzli, B.; Autschbach, F.; Meuer, S.; Buchler, M.W.; Friess, H. Inhibition of heme oxygenase-1 increases responsiveness of pancreatic cancer cells to anticancer treatment. Clin. Cancer Res. 2005, 11, 3790-3798. [CrossRef]

77. So, K.Y.; Kim, S.H.; Jung, K.T.; Lee, H.Y.; Oh, S.H. MAPK/JNK1 activation protects cells against cadmium-induced autophagic cell death via differential regulation of catalase and heme oxygenase-1 in oral cancer cells. Toxicol. Appl. Pharmacol. 2017, 332, 81-91. [CrossRef]

78. Chien, M.H.; Yang, W.E.; Yang, Y.C.; Ku, C.C.; Lee, W.J.; Tsai, M.Y.; Lin, C.W.; Yang, S.F. Dual Targeting of the p38 MAPKHO-1 Axis and cIAP1/XIAP by Demethoxycurcumin Triggers Caspase-Mediated Apoptotic Cell Death in Oral Squamous Cell Carcinoma Cells. Cancers 2020, 12, 703. [CrossRef] 